\title{
Development of high-resolution future ocean regional projection datasets for coastal applications in Japan
}

\author{
Shiro Nishikawa ${ }^{1 *}$, Tsuyoshi Wakamatsu ${ }^{2,3}$, Hiroshi Ishizaki ${ }^{1}$, Kei Sakamoto ${ }^{4}$, Yusuke Tanaka $^{1}$, Hiroyuki Tsujino ${ }^{4}$, \\ Goro Yamanaka ${ }^{4}$, Masafumi Kamachi ${ }^{1}$ and Yoichi Ishikawa ${ }^{1}$
}

\begin{abstract}
In this study, we developed two high-resolution future ocean regional projection datasets for coastal applications in Japan, in which we made use of dynamical downscaling via regional ocean models with atmospheric forcing from two climate models (i.e., MIROC5 and MRI-CGCM3) participating in Coupled Model Intercomparison Project Phase 5 (CMIP5) under historical, representative concentration pathway (RCP) 2.6, and RCP8.5 scenarios. The first dataset was an eddy-resolving 10-km resolution product covering the North Pacific Ocean area and ranging continuously from 1981 to 2100, in which the Kuroshio current and mesoscale structures were reasonably resolved. The second dataset was a 2-km resolution product covering the regional domain surrounding Japan and comprising 10-15-year time slices, in which the coastal geometry and current structure were resolved even more realistically. An important feature of these datasets was the availability of reference datasets based on atmospheric and oceanic reanalysis data for cross-validation during the historical run period. Using these reference datasets, biases of regional surface thermal properties and the Kuroshio states during the historical run period were evaluated, which constitute important information for users of the datasets. In these downscaled datasets, the future surface thermal responses were generally consistent with those of their original data. Utilizing the high-resolution property of the downscaled data, possible future impact analyses regarding coastal phenomena such as strait throughflows, coastal sea level variability, and the Kuroshio intrusion phenomenon into bays ("Kyucho" phenomenon) were demonstrated and the important role of the Kuroshio state representation was indicated, which had proved difficult to analyze using the low-resolution projection data. Given these properties, the present datasets would be useful in climate change adaptation studies regarding the Japanese coastal region.
\end{abstract}

Keywords: Ocean future projection, Dynamical downscaling, Ocean model, CMIP5

\section{Introduction}

The North Pacific Ocean (NPO) will experience a significant transition by the end of the twenty-first century, in accordance with the current trend of global climate change, including substantial oceanographic warming (IPCC 2013, 2014; Alexander et al. 2018). At present, NPO coastal communities are facing challenges in the

\footnotetext{
* Correspondence: snishika@jamstec.go.jp

'Japan Agency for Marine-Earth Science and Technology, 3173-25

Showa-machi, Kanazawa-ku, Yokohama 236-0001, Japan

Full list of author information is available at the end of the article
}

establishment of adaptation plans to mitigate the impact of climate change on their socioeconomic activities. The current best available resource for projecting future ocean states is the Coupled Model Intercomparison Project Phase 5 (CMIP5) model ensemble dataset (Taylor et al. 2012), which has been extensively used to assess future projections of the coastal marine environment. However, this approach faces problems in fulfilling the current demands for coastal applications. Since a coupled earth system model produces CMIP5 data, the data resolutions are kept relatively coarse, and additional 
downscaling efforts, whether dynamical, statistical, or hybrid, are required for coastal applications. For instance, the Kuroshio representations in CMIP5 models are usually too broad to measure the detailed impacts on coastal communities, and not all key variables are available for assessment due to limited storage space. In several studies, ocean downscaling has been performed using climate model projection products (i.e., CMIP) that focus on the western North Pacific region (e.g., Sato et al. 2006; Liu et al. 2016). However, their resolutions were eddy-permitting (about $30 \mathrm{~km}$ ) and insufficient for assessing the future climate change impacts on the Kuroshio current or coastal problems in the NPO. High-resolution ocean downscaling using CMIP products for regional/coastal applications has been achieved for world ocean regions, such as the Northwest Atlantic Ocean (e.g., Alexander et al. 2020; see their introduction for further references), the northwest European shelf regions (e.g., Hermans et al. 2020; see their introduction for additional references), and several other coastal regions (e.g., Sun et al. 2012; Hermann et al. 2016; Toste et al. 2017; Xiu et al. 2018). However, such a highresolution dynamical downscaling approach seems to have rarely been used for the NPO.

The Social Implementation Program on Climate Change Adaptation Technology (SI-CAT) project was conducted between 2016 and 2020, supported by the Ministry of Education, Culture, Sports, Science and Technology, Japan (SI-CAT 2020). One of the primary tasks of the project was to develop reliable technologies and high-resolution future ocean projection information to assist the local government in Japan in developing climate change adaptation plans. At the beginning of the project, the ocean future projection task team conducted a series of surveys on the parameters of future ocean state projections needed in developing adaptation plans. The surveys suggested that high-resolution sea level, sea surface temperature, and surface current speed, of the order of a 2-km horizontal resolution, are the important parameters for assessing local climate change impacts, e.g., coastal environment conservation, coastal disaster prevention, and fisheries (SI-CAT 2020). Ocean boundary variables for a coastal-scale ocean circulation and wave model, for the further refinement of the projected ocean state, have also been requested for the assessment of coastal erosion and storm surge (e.g., Troselj et al. 2018). Therefore, in an effort to satisfy these demands, we designed dynamical downscaling experiments that utilized CMIP5 products to advance our future projections of the coastal ocean state around Japan.

The ensemble projected future ocean states would be regenerated by driving eddy-resolving regional ocean models with ensemble atmospheric forcing from CMIP5. Our approach was unique in the following ways: (i) reference ocean states, generated from the same ocean models forced by an atmospheric reanalysis forcing, were provided for evaluation of the models; (ii) the downscaled ocean states were validated against a highresolution ocean state reanalysis; and (iii) a set of CMIP5 models were selected based on the availability of threehourly atmospheric components in the historical, representative concentration pathways (RCP) 2.6, and RCP8.5 periods for historical and future projections. In light of the background outlined above, we developed highresolution future ocean projection datasets under the SICAT project, collectively termed the future ocean regional projection (FORP) dataset.

This paper describes the development of this dataset (including the ocean model system, atmospheric forcings, experimental designs, and the dataset specifications) and briefly outlines the models' performance and validation, focusing on the mean surface thermal properties and the Kuroshio and coastal current structures around Japan. Section 2 reports the methods and procedures, and Section 3 validates the products. Section 4 summarizes and discusses the findings, conveys the primary concluding points, and identifies the remaining tasks for future research.

\section{Methods}

In order to create high-resolution future ocean projection datasets for application in Japan, we developed two regional ocean models with different horizontal resolution and conducted a series of numerical experiments for future ocean state projections for the period 1981 to 2100. The future projections were produced via the dynamical downscaling of the selected global climate projection datasets from CMIP5, namely MIROC5 (Watanabe et al. 2010) and MRI-CGCM3 (Yukimoto et al. 2012). As a result, the large-scale climate projections from CMIP5 were dynamically extrapolated using the regional ocean models to an ocean mesoscale of $\mathrm{O}(10 \mathrm{~km})$ and a coastal scale of $\mathrm{O}(2 \mathrm{~km})$. Crossvalidation data for the ocean projection products during the historical run period were also provided by utilizing an ocean reanalysis data and performing reference simulations under an atmospheric reanalysis forcing. The outline of the dataset generation was as follows. First, the $10-\mathrm{km}$ ensemble data of historical and future ocean state projections were generated from the outer regional ocean model utilizing the constructed atmospheric forcings. Then, the $2-\mathrm{km}$ downscaled data were generated from the inner regional ocean model via the one-way (off-line) nesting method for several time slices from the historical and future terms.

\subsection{Regional ocean models and reference data}

The regional ocean models comprised the NPO model with a $10-\mathrm{km}$ horizontal resolution (NP10) and the 
nested ocean model surrounding Japan with a 2-km horizontal resolution (JPN02). Figure 1 presents the model domains. Both models were developed based on the ocean general circulation model, i.e., the Meteorological Research Institute Community Ocean Model version 4 (MRI.COMv4; Tsujino et al. 2017). Table 1 presents the detailed configurations of each model. The bathymetry of the JPN02 model was based on the JTOPO30v2 data provided by the Marine Information Research Center, and several detailed settings (e.g., physical schemes and parameters) of the JPNO2 model were similar to those described by Sakamoto et al. (2016).

We adopted a four-dimensional variational (4D-VAR) ocean reanalysis dataset for the western North Pacific (FORA-WNP30) (Usui et al. 2017) as a reference dataset. This was an open dataset of ocean reanalysis covering the years 1982-2014. Various observational data, including temperature-salinity profiles from ship and float databases, as well as satellite-based data on sea surface temperature (SST) and sea level anomalies, were synthesized using the 4D-VAR method. For the atmospheric reanalysis data, the Japanese 55-year Reanalysis (JRA-55) (Kobayashi et al. 2015) was used for the surface boundary condition to produce FORA-WNP30 and to conduct reference runs of the NP10 and JPN02 (see the following subsections). The good reproducibility of the ocean state in the western North Pacific, especially regarding the Kuroshio and Oyashio currents and surface thermal properties around Japan, has been confirmed (Usui et al. 2017). Therefore, we used this ocean reanalysis dataset as a reference state to validate the present ocean model results.
Note that FORA-WNP30 shared its ocean model component MRI.COM and vertical grid coordinates with the NP10 and JPN02 configurations, and its horizontal resolution was basically the same as that of the NP10 (Table 1).

\subsection{Construction of the atmospheric forcings}

The atmospheric forcings, used for the surface boundary condition of the regional ocean models, were constructed from the JRA-55 atmospheric reanalysis data and the MIROC5 and MRI-CGCM3 (hereafter, CMIP5) products. The historical scenarios were chosen for the CMIP5 control runs, which were derived from the observed natural and anthropogenic atmospheric compositions and covered the period from 1960 to 2005. For the CMIP5 climate projection runs, two RCP scenarios (Moss et al. 2010; Vuuren et al. 2011), namely RCP2.6 and RCP8.5, were chosen, covering the period from 2006 to 2100 . The key considerations in the selection of the MIROC5 and MRI-CGCM3 among the CMIP5 model ensembles were as follows: (i) the representation in the NPO was considered and carefully calibrated, as they were developed in Japan (e.g., Watanabe et al. 2010; Yukimoto et al. 2012), and (ii) the eight surface variables with three-hourly temporal resolution (Table 2) were complete and available for the historical, RCP2.6, and RCP8.5 scenarios to construct the forcing data. The three-hourly resolution was chosen so that the upper ocean momentum flux and mixed layer dynamics would be well-represented in the ocean model integrations. All of the atmospheric variables of MIROC5 and MRICGCM3 were downloaded from the Earth System Grid

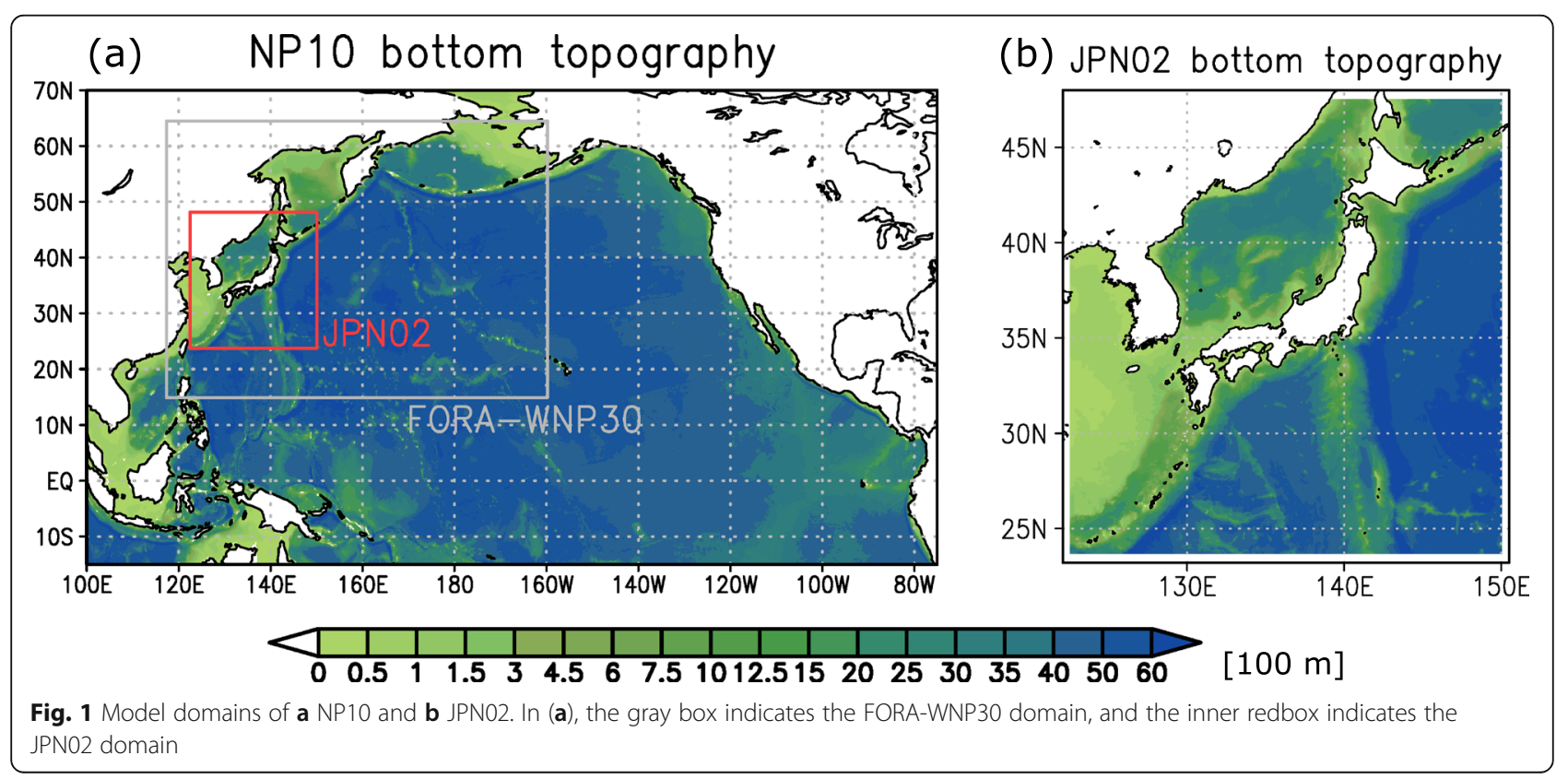


Table 1 Configurations of the regional ocean model system (NP10, JPN02) and the ocean reanalysis (FORA-WNP30, Usui et al. 2017)

\begin{tabular}{|c|c|c|c|}
\hline & NP10 & JPN02 & FORA-WNP30 \\
\hline Use & Reginal ocean model (outer) & Regional ocean model (inner) & Reference data \\
\hline Domain & $100^{\circ} \mathrm{E}-75^{\circ} \mathrm{W}, 15^{\circ} \mathrm{S}-70^{\circ} \mathrm{N}$ (Fig. 1a) & $122.6^{\circ} \mathrm{E}-150^{\circ} \mathrm{E}, 23.7^{\circ} \mathrm{N}-47.5^{\circ} \mathrm{N}$ (Fig. 1b) & $\begin{array}{l}117^{\circ} \mathrm{E}-160^{\circ} \mathrm{W}, 15^{\circ} \mathrm{N}-65^{\circ} \mathrm{N} \text { (gray } \\
\text { rectangle in Fig. 1a) }\end{array}$ \\
\hline Model code & MRI.COMv4 (Tsujino et al. 2017) & MRI.COMv4 (Tsujino et al. 2017) & MRI.COM ver2.4 (Tsujino et al. 2010) \\
\hline $\begin{array}{l}\text { Resolution } \\
\text { (hor.) }\end{array}$ & $1 / 10^{\circ} \times 1 / 10^{\circ}$ (approx. $10 \mathrm{~km}$ ) & $1 / 30^{\circ} \times 1 / 50^{\circ}$ (approx. $2 \mathrm{~km}$ ) & $1 / 10^{\circ} \times 1 / 10^{\circ}$ \\
\hline $\begin{array}{l}\text { Resolution } \\
\text { (vert.) }\end{array}$ & 1 m (surface)-600 m (bottom) & Same as the NP10 & Same as the NP10 \\
\hline Grid size & $1852 \times 852$ (hor.), 54 (vert.) & $826 \times 1194$ (hor.), 54 (vert.) & $673 \times 442$ (hor.), 54 (vert.) \\
\hline $\begin{array}{l}\text { Atmos. } \\
\text { forcing }\end{array}$ & JRA-55, CMIP5 (3-hourly) & JRA-55, CMIP5 (3-hourly) & JRA-55 (3-hourly) \\
\hline $\begin{array}{l}\text { Lateral } \\
\text { boundary } \\
\text { condition }\end{array}$ & $\begin{array}{l}\text { WOA monthly } T / S \text { climatology, kinematically } \\
\text { no flux }\end{array}$ & One-way nesting with the NP10 & WOA monthly $\mathrm{T} / \mathrm{S}$ climatology \\
\hline $\begin{array}{l}\text { Surface } \\
\text { restoring }\end{array}$ & WOA monthly SSS & $\begin{array}{l}\text { Climatological monthly SSS from the } \\
\text { NP10 }\end{array}$ & WOA monthly SSS \\
\hline River input & N/A & JRA55-do (Suzuki et al. 2018) based data & N/A \\
\hline $\begin{array}{l}\text { Physical } \\
\text { processes }\end{array}$ & $\begin{array}{l}\text { Included: Sea-ice, fresh water in terms of salt } \\
\text { flux. Not included: tides, river input, thermal } \\
\text { expansion. }\end{array}$ & $\begin{array}{l}\text { Included: Sea-ice, fresh water in terms of } \\
\text { salt flux, river input. Not included: tides, } \\
\text { thermal expansion. }\end{array}$ & $\begin{array}{l}\text { Included: Sea-ice, fresh water in terms of } \\
\text { salt flux. Not included: tides, river input, } \\
\text { thermal expansion. }\end{array}$ \\
\hline
\end{tabular}

Federation server (https://esgf.llnl.gov/) and interpolated with the standard $320 \times 160$ Gaussian grid. The JRA-55 forcing data utilized a $640 \times 320$ Gaussian grid. The atmospheric variables were then used to calculate the ocean driving surface fluxes via bulk formulas within MRI.COMv4, in which the SST from the ocean model was used (see Tsujino et al. 2017 for details). Note that the surface freshwater flux was converted to a salinity flux in the models; therefore, over the model integrations, the total volume within the model domain was conserved.

Following the spatial interpolation into the standard grid, the CMIP5 (MIROC5 and MRI-CGCM3) atmospheric variables were slightly tuned against the JRA-55

Table 2 Atmospheric variables used for constructing the model forcing from CMIP5 (MIROC5 and MRI-CGCM3)

\begin{tabular}{ll}
\hline Variables & \\
\hline huss & Near-surface specific humidity \\
pr & Precipitation \\
psl & Sea level pressure \\
rlds & Surface downwelling longwave radiation \\
rsds & Surface downwelling shortwave radiation \\
tas & Air temperature \\
uas & Eastward near-surface wind speed \\
vas & Northward near-surface wind speed \\
\hline
\end{tabular}

data. We compared the variability of each surface variable (Table 2) from the CMIP5 data with that from the JRA-55 and found that the CMIP5 data included much larger variability in the short-term (daily) frequency range, which induced computational instability in the ocean model integration, specifically in the sea ice module. To reduce this unrealistically large short-term variability, we applied temporal smoothing with a five-point periodic moving window to the CMIP5 data at each three-hourly time step across 5 days. Note that this smoothing retained the diurnal variation.

The river input effect was implemented in the JPN02 model as follows: The freshwater flux along the Japan coast was based on the daily mean river runoff data from the reanalysis-based JRA55-do dataset (Suzuki et al. 2018). The daily mean gridded runoff data from JRA55-do with a horizontal resolution of $0.25^{\circ}$ were merged with the CMIP5 freshwater flux data. In the historical run period, the daily mean runoff data were simply incorporated into the freshwater flux. In the RCP scenario run period, the newly constructed future river runoff data were merged, which were constructed from the JRA55-do river runoff and CMIP5 precipitation data. First, the CMIP5 precipitation data were averaged for a region surrounding Japan $\left(123.5^{\circ} \mathrm{E}-148.75^{\circ} \mathrm{E}, 25^{\circ} \mathrm{N}-46.75^{\circ} \mathrm{N}\right)$. Assuming that the future river runoff change roughly corresponds to the precipitation change integrated within the region surrounding Japan, the following ratio was computed. The ratio of the annual mean domain-averaged precipitation of each year to the 20-year (1996-2015) mean domain-averaged 
precipitation was calculated for each year in each CMIP5 case. The yearly time series of the precipitation change ratio was then multiplied by the 20-year (1996-2015) mean daily JRA55-do river runoff data to derive the future river runoff data in the RCP run period for each CMIP5 case. (Note that this was only an assumption for the future run and not based on any detailed relationship within the historical run period.)

\subsection{Evaluation of the ensemble atmospheric forcing}

To characterize the differences among the selected CMIP5 forcings in terms of their impact on ocean circulation, the Sverdrup transport stream function (STSF) was calculated from the monthly mean wind stress for each CMIP5 and JRA-55 forcing. After applying decadal averaging to the STSF, the time series of the maximum STSF, minimum STSF, and latitude of zero STSF measured at $160^{\circ} \mathrm{E}$ were plotted (Fig. 2). From basic winddriven ocean circulation theory (e.g., Pedlosky 1996), the maximum STSF corresponds to the strength of the subtropical gyre, the minimum STSF corresponds to the strength of the subpolar gyre, and the latitude of zero STSF reflects the border of the subtropical and subpolar gyres (e.g., Aoki and Kutsuwada 2008). During the JRA55 run period (1981-2015), the maximum STSFs of both CMIP5 forcings had clear offsets from that in the JRA55 (Fig. 2a). MIROC5 had an offset of about $+2 \mathrm{~Sv}(=1$ $\left.0^{6} \mathrm{~m}^{3} \mathrm{~s}^{-1}\right)$, and MRI-CGCM3 had an offset of about +4 to $+5 \mathrm{~Sv}$. Offsets could also be found in the minimum STSF: MIROC5 had an offset of about $+25 \mathrm{~Sv}$, and MRI-CGCM3 had one of about +15 Sv (Fig. 2b). This indicated that both of the CMIP5 atmospheric forcing data had a bias toward generating stronger subtropical gyres and weaker subpolar gyres than the JRA55-driven ocean circulation according to linear wind-driven ocean circulation theory. The latitudes of zero STSF of the CMIP5 forcing data were all around $40^{\circ} \mathrm{N}$ during the JRA-55 run period, i.e., offset by about $3^{\circ}$ south compared to that of the JRA-55. This suggests that the MIROC5/MRI-CGCM3-forcing-driven ocean circulation had an equatorward-shifted bias regarding the boundary of the subtropical and subpolar gyres.

\subsection{Experimental design of the NP10 future projection simulation}

Table 3 presents the periods of the historical and future projection experiments with the NP10 model. The historical and future ocean state projections were generated as follows: To start with, the NP10 ocean model was integrated with CMIP5 historical atmospheric forcings from 1960 to 2005. Following the end condition of the historical run, it was further integrated by switching the atmospheric forcing from the historical-run-based forcings to the CMIP5 ensemble future projection-based (RCP2.6 and RCP8.5) atmospheric forcings. The NP10 model was also integrated with the JRA-55 atmospheric reanalysis forcing from 1958 to 2015 for cross-validation purposes. Both model integrations forced by the CMIP5 historical run-based atmospheric forcings and JRA-55 atmospheric forcing began from a static state, initialized with temperature and salinity from the World Ocean Atlas (WOA) monthly climatology (Levitus and Boyer 1994; Levitus et al. 1994). The first 20 years (1958/ 1960-1980) were considered the models' spin-up period and were excluded from the FORP datasets. For the boundary conditions, there was no kinematic flux at the lateral boundaries. The temperature and salinity within the $2^{\circ}$ band along the lateral boundaries were restored to the values of the WOA monthly climatology. In all experiments with the NP10 model (Table 3), the model settings (Table 1), lateral boundary condition, and initial condition of the historical run were the same; the only difference was the surface forcing. This $10-\mathrm{km}$ dataset from the NP10 simulations was termed FORP-NP10.

\subsection{Experimental design of the JPNO2 downscaling simulation}

We employed time slice and dynamical downscaling methods to produce higher resolution $(2 \mathrm{~km})$ downscaled historical and future projection products. Note that the JPN02 ocean model required large computational and storage resources as well as CPU hours. The selected time slice periods are listed in Table 4, composed of 11 slices with 10- or 15-year integration periods (with a total of 120 years). The initial condition of each time slice was derived from the corresponding restart file of the parent model (NP10) integrations. The spin-up period of each time slice with the JPN02 model was about 1 month without any nudging processes. The oneway (off-line) nesting method (see Tsujino et al. 2017 for details) was used for the dynamical downscaling from the NP10 to the JPN02. The daily mean outputs from the parent model (NP10) were used for the lateral boundaries of the child model (JPN02). The 10-year (1996-2005) downscaling period from the historical runs was incorporated by the MIROC5, MRI-CGCM3, and JRA-55 forced cases (Table 4). However, the time slice periods of the downscaling for the future projection were only covered by the MRI-CGCM3 forced case for both the RCP2.6 and RCP8.5 runs (Table 4) due to limitations in computational resources. Surface forcing was common between the parent and child models for each downscaling experiment. On the basis of these procedures, we constructed a higher-resolution downscaling dataset using the FORP-NP10 and the JPN02 model, which we termed FORP-JPN02. 


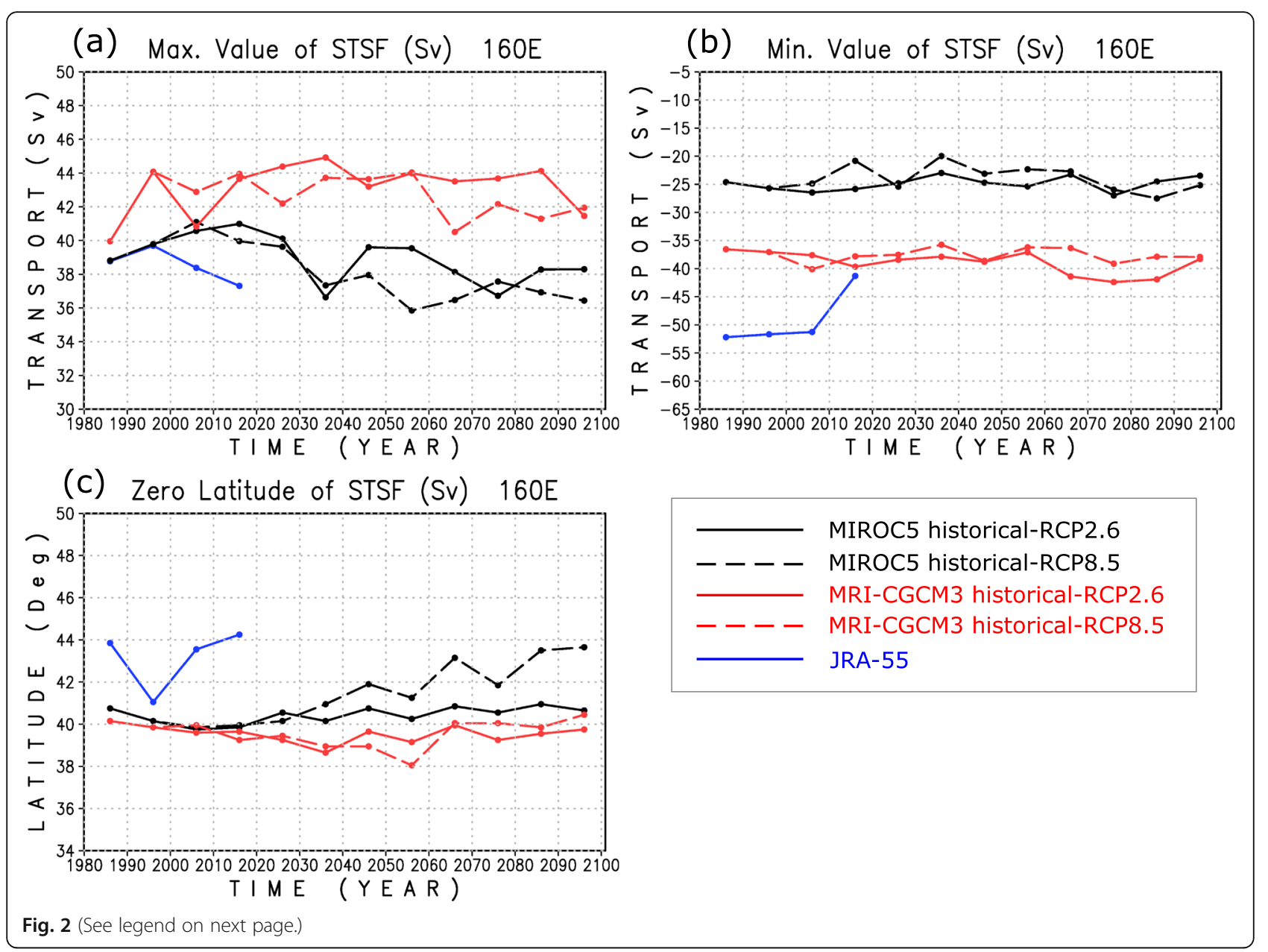

\subsection{Basic specifications of the FORP datasets}

The FORP-NP10 and FORP-JPN02 datasets included the following variables: sea surface height (SSH), potential temperature, salinity, zonal velocity, and meridional velocity. The spatial domains of these datasets corresponded to those of the respective ocean models. The time resolution of each dataset was the monthly mean for FORP-NP10 and the daily mean for FORPJPN02. The file formats for the distribution were netCDF. Table 5 summarizes these basic specifications of the datasets.

\section{Results}

\subsection{Representation of the general ocean state and future projections around Japan}

Figure 3 displays the 10-year (1996-2005) mean maps of the ocean heat content $(\mathrm{OHC})$ around Japan calculated from the NP10 and JPN02 historical results (JRA-55, MIROC5, and MRI-CGCM3), compared with the ocean reanalysis data FORA-WNP30 (Fig. 3a) and the original CMIP5 ocean products (Fig. 3b, c). Here, the $\mathrm{OHC}$ was derived by averaging the temperature of the upper 0 $700 \mathrm{~m}$ layer. As temperature dominates density in this region, the $\mathrm{OHC}$ contours closely reflect the surface flows. On the basis of this relationship, the Kuroshio and Oyashio (the western boundary currents of the NPO) and Tsushima and Tsugaru coastal currents (see the next subsection for details) around Japan are represented by the $\mathrm{OHC}$ frontal structures in the $\mathrm{OHC}$ map, as observed in the $10-\mathrm{km}$ ocean reanalysis data (Fig. 3a). These mean surface current properties were found to be fairly common among the reanalysis and high-resolution simulation results of the NP10 and JPN02 (Fig. 3a, d-i). Thus, the NP10 and JPN02 ocean models were regarded as having the ability to reproduce climatological surface thermal and kinematical ocean states under given reasonably accurate atmospheric forcing conditions. In contrast, the original MIROC5 and MRI-CGCM3 (hereafter, original CMIP5) ocean products (Fig. 3b, c) did not represent such details of the western boundary currents and coastal currents around Japan due to their coarse model resolutions. 
(See figure on previous page.)

Fig. 2 Time series of the 10-year mean STSF (Sv) at $160^{\circ} \mathrm{E}$, calculated from wind stress of two CMIP5 (MIROC5 (black lines) and MRI-CGCM3(red lines)) and the JRA-55 (blue lines) atmospheric data. For the CMIP5 cases, the solid lines denote RCP2.6 and the dashed lines RCP8.5 where the historical data (1981-2005) were included. a Maximum STSF. b Minimum STSF. c Latitude of zero transport. Note that the last value of JRA-55 in each panel is a 5-year (2011-2015) mean

In Fig. 4, the differences (biases) in the area mean $\mathrm{OHCs}$ from the reanalysis data (FORA-WNP30) were evaluated for the four rectangular regions presented in Fig. 3d, namely the East China Sea (ECS) region, the North Pacific subtropical gyre region along the Kuroshio (KUR), the mixed water region (MWR) north of the Kuroshio, and the Sea of Japan (SOJ) region. As is clear from the OHC maps (Fig. 3b, c), the original CMIP5 products (red and blue bars) exhibited relatively large regional biases, e.g., a cold bias in the ECS and KUR (i.e., the North Pacific subtropical gyre) for both the MIROC5 and MRI-CGCM3 and a significant warm bias over the $\mathrm{SOJ}$ for the MIROC5. These biases were effectively reduced in the corresponding NP10 and JPN02 downscaling results (orange and light blue bars). The biases of the NP10 and JPN02 results over the ECS and KUR were generally small, within $\pm 0.5^{\circ} \mathrm{C}$ and the standard deviation (SD) range of the reanalysis (the error bars in Fig. 4), except for those in the ECS for the JPN02 cases. Relatively large biases were found in the northern regions (MWR and SOJ): in the MWR, $+2{ }^{\circ} \mathrm{C}$ and $-1{ }^{\circ} \mathrm{C}$ for the JRA-55 and MRI-CGCM3 forced cases respectively, and in the SOJ, $+1{ }^{\circ} \mathrm{C}$ to $+1.5{ }^{\circ} \mathrm{C}$ for the MIROC5 and JRA -55 forced cases, which were beyond the SD ranges of the reanalysis. These surface thermal biases would prove important for FORP data users to assess future ocean regional impacts.

In Fig. 5, the vertical sections at $145.5^{\circ} \mathrm{E}$ of the potential density and zonal velocities are compared to examine the offshore thermal and current structures in the NPO. The eastward flow with a meridional density gradient at $40^{\circ}$ $\mathrm{N}-42^{\circ} \mathrm{N}$, as shown in the ocean reanalysis (Fig. $5 \mathrm{a}$ ), corresponded to the extension of the Oyashio current (or subarctic front) (e.g., Yasuda 2003; Kida et al. 2016). The position and vertical structure were generally wellreproduced in the NP10 and JPN02 results (Fig. 5d-g), apart from the MIROC5 and MRI-CGCM3 forced results of the JPN02 where the positions stood at $38^{\circ} \mathrm{N}-40^{\circ} \mathrm{N}$ (Fig. 5h, i). The relationship between the relative strengths for three NP10 cases (JRA-55 > MRI-CGCM3 > MIROC5) may be explained by the STSFs presented in Fig. 2b. However, defining and evaluating the Oyashio is a difficult problem and this topic, based on the FORP data, is discussed in Nishikawa et al. (2020). The eastward flow with a strong meridional density gradient at $32^{\circ} \mathrm{N}-37^{\circ} \mathrm{N}$ (Fig. 5a) corresponded to the Kuroshio Extension (KE) (e.g., Qiu et al. 2006). Among the reanalysis and simulation results (Fig. 5a, $\mathrm{d}-\mathrm{i}$ ), the basic KE jet structure (the thermal wind relationship) was essentially consistent. The $\mathrm{KE}$ axis position in the MIROC5 and MRI-CGCM3 forced results (32.5 N, in Fig. 5e, $\mathrm{f}, \mathrm{h}, \mathrm{i})$ was further to the south than in the reanalysis and the JRA-55 forced results $\left(35^{\circ} \mathrm{N}-36^{\circ} \mathrm{N}\right.$, in Fig. 5a, d, g). This apparent bias in the KE latitudes in the MIROC5 and MRICGCM3 forced products was attributed to the bias in the wind stress distribution in their original atmosphere products. The latitude of zero STSF at $160^{\circ} \mathrm{E}$ (Fig. 2c), calculated from the wind data of JRA-55 and MIROC5/MRI-CGCM3, indicated that the boundary of the subtropical and subpolar gyres expected in the MIROC5/MRI-CGCM3 forcings was located approximately $3^{\circ}$ further south than that expected in the JRA55 forcing. This difference could affect the evaluation of the future ocean state in the coastal region around Japan, as is discussed below. Note that the resolution of the original CMIP5 products (Fig. 5b, c) was insufficient for resolving the Kuroshio and Oyashio jet structures.

Figure 6 presents the time series of the 10-year mean Kuroshio transports over the historical and RCP2.6/ RCP8.5 run periods (i.e., 1981 to 2100) from the three NP10 results (MIROC5, MRI-CGCM3, and JRA-55). Here, based on the work of Imawaki et al. (2001), the Kuroshio transport was approximated from the volume transport stream function between Shikoku Island $\left(34^{\circ}\right.$ $\left.\mathrm{N}, 134^{\circ} \mathrm{E}\right)$ and an offshore point $\left(26^{\circ} \mathrm{N}, 140^{\circ} \mathrm{E}\right)$. The offshore point for the NP10 results was located slightly east of Imawaki et al.'s (2001) observation line after analyzing the long-term variance in the transport stream function to minimize the influence of the Kuroshio recirculation. During the historical run period (1981-2005), the mean transports of three NP10 results were generally close to

Table 3 Periods of historical and future projection experiments by the NP10

\begin{tabular}{llll}
\hline Forcing (CMIP5, JRA-55) & Historical (JRA-55 hindcast) & RCP2.6 & RCP8.5 \\
\hline MIROC5 & $1960-2005$ & $2006-2100$ & $2006-2100$ \\
MRI-CGCM3 & $1960-2005$ & $2006-2100$ & $2006-2100$ \\
JRA-55 & $1958-2015$ & & \\
\hline
\end{tabular}


Table 4 Periods of time-sliced downscaling experiments by the JPN02

\begin{tabular}{llll}
\hline Forcings (CMIP5, JRA-55) & Historical (JRA-55 hindcast) & RCP2.6 & RCP8.5 \\
\hline MIROC5 & $1996-2005$ & & \\
MRI-CGCM3 & $1996-2005$ & $2086-2100$ & $2006-2015,2016-2025,2026-2035,2036-2045,2046-2055,2086-2100$ \\
JRA-55 & $1996-2005$, 2006-2015 & & \\
\hline
\end{tabular}

the value observed (42 Sv) by Imawaki et al. (2001). The transports of the JRA-55 and MIROC5 forced results were at a similar level, approximately $38 \mathrm{~Sv}$, whereas that of the MRI-CGCM3 forced result was about $42 \mathrm{~Sv}$. The discrepancies among the models are consistent with the analysis of the maximum STSF at $160^{\circ} \mathrm{E}$ (Fig. 2a). In the RCP8.5 cases from the MIROC5 and MRI-CGCM3 forced results (the dashed lines in Fig. 6), a gradual reduction in the Kuroshio transport was observed, whereas in the RCP2.6 cases (black and red solid lines in Fig. 6), no clear trends were apparent. These future Kuroshio trends have not been noted in past studies on future projections of the Kuroshio, although the intensification and/or northward shifting trend of the future KE has been previously noted (e.g., Sakamoto et al. 2005; Sato et al. 2006; Li et al. 2017). However, a detailed investigation into this is beyond the scope of this paper, but it is an interesting future research topic.

The transitions (1981-2100) of the OHC against the 1986-2005 mean are depicted in Fig. 7 for the NP10 results (Fig. 7a) and the original CMIP5 ocean products (Fig. 7b). While the difference among the scenarios and models was relatively small in the near future term (2030-2050), it expanded after 2070. These general $\mathrm{OHC}$ transition properties (tendency and variability) were found to be similar between the NP10 and their original results.

Figure 8 presents the $\mathrm{OHC}$ changes from 1996-2005 to 2086-2095 for the four rectangular regions presented in Fig. 3d, with the NP10, JPN02, and their original products, where the error bars denote the range from RCP2.6 to RCP8.5 and the box bars indicate their means.
In the RCP8.5 cases (the top of the error bars), the $\mathrm{OHC}$ changes range from +1.5 to $+2.0{ }^{\circ} \mathrm{C}$ on the ECS and KUR, and they reach $+2.0{ }^{\circ} \mathrm{C}$ to $+3.5^{\circ} \mathrm{C}$ on the SOJ and MWR. In the RCP2.6 cases (the bottom of the error bars), the $\mathrm{OHC}$ changes were relatively uniform among the regions and within $+0.5{ }^{\circ} \mathrm{C}$ to $+1.0{ }^{\circ} \mathrm{C}$ except on the SOJ for the MIROC5 cases $\left(+1.5{ }^{\circ} \mathrm{C}\right)$. In general, the MIROC5 cases indicated greater warming than the MRICGCM3 ones, and the differences between the MIROC5 and MRI-CGCM3 were somewhat larger over the marginal seas (SOJ and ECS). There appeared to be no significant gaps between the downscaling and their parent/ original results for the same atmospheric forcing cases, suggesting that the difference between the dynamical downscaling and non-downscaling cases may not be statistically significant with respect to the regional $\mathrm{OHC}$ future response.

In summary, the MIROC5 and MRI-CGCM3 forced results of the NP10 and JPN02 reasonably represented large-scale upper ocean thermal states around Japan, with some improved regional biases in the historical term and consistent future responses with their originals. Because of the high horizontal resolutions of $\mathrm{O}(10 \mathrm{~km})$ and $\mathrm{O}(2 \mathrm{~km})$, they reproduced the important current systems, including the Kuroshio and Oyashio currents, which were not well-resolved in the original CMIP5 data of $\mathrm{O}(100 \mathrm{~km})$. However, it should be noted that the latitudinal positions of the Kuroshio and Oyashio tended to be southward biased, which can presumably be explained by the latitudinal positions of mid-latitude westerly, which were also biased southward in the original MIROC5 and MRI-CGCM3 atmospheres.

Table 5 Outline of the basic specifications of the FORP datasets (FORP-NP10 and FORP-JPN02)

\begin{tabular}{lll}
\hline & FORP-NP10 & FORP-JPN02 \\
\hline Main variables & $\begin{array}{l}\text { Sea surface height, potential temperature, salinity, zonal } \\
\text { velocity, and meridional velocity }\end{array}$ & $\begin{array}{l}\text { Sea surface height, potential temperature, salinity, zonal } \\
\text { velocity, and meridional velocity }\end{array}$ \\
Time resolution & Monthly mean & Daily mean \\
Format & NetCDF & NetCDF \\
Period & (see Table 3) & (see Table 4) \\
$\begin{array}{l}\text { Domain and } \\
\text { resolution }\end{array}$ & (As the NP10, see Table 1) & (As the JPN02, see Table 1) \\
\hline
\end{tabular}



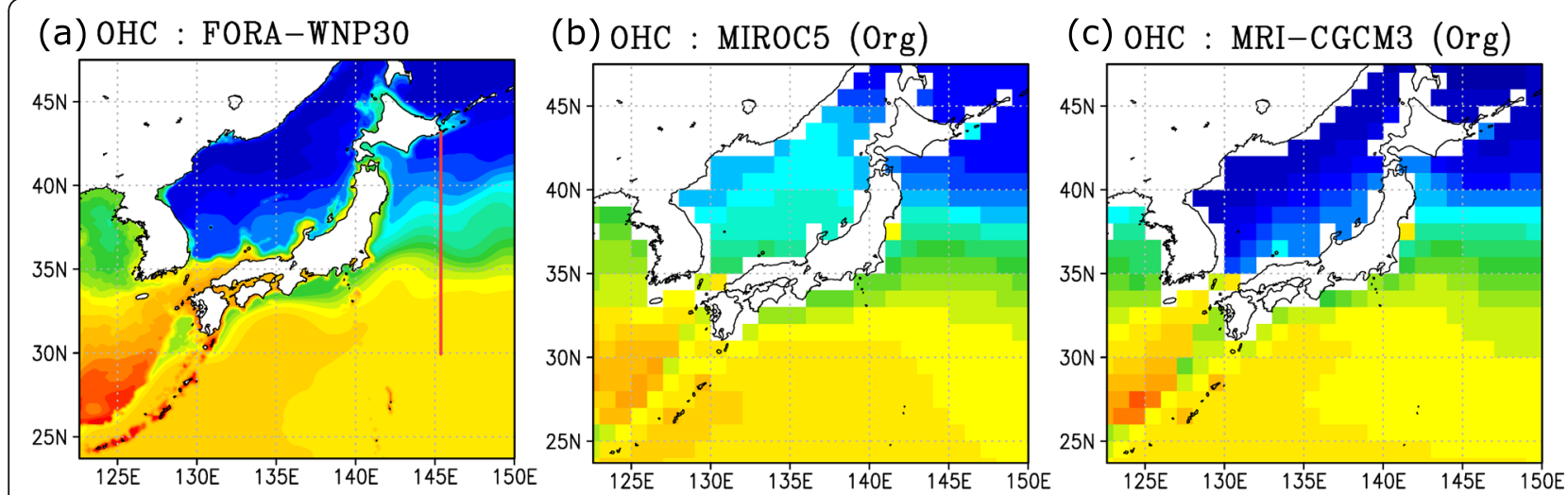

(d) OHC : JRA55 (NP10)

(e) OHC : MIROC5 (NP10)
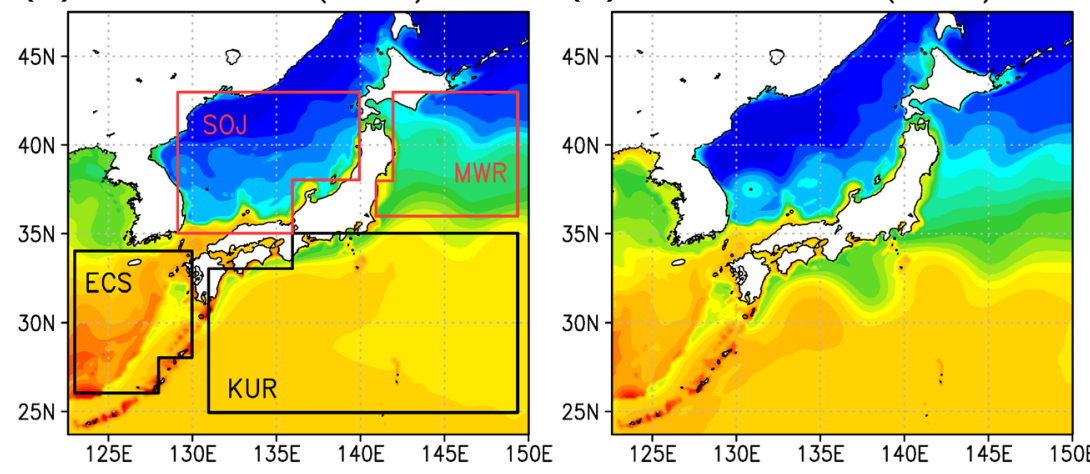

(f) OHC : MRI-CGCM3 (NP10)

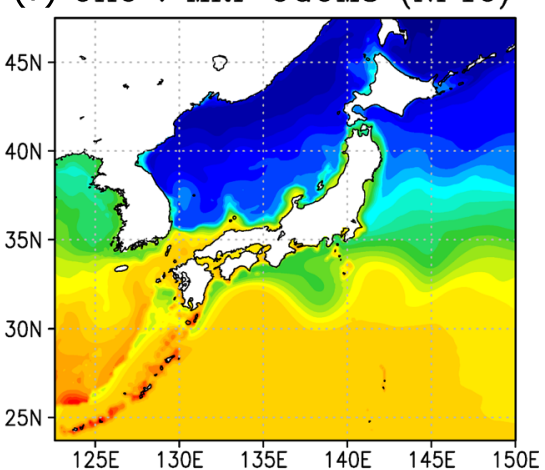

(h) OHC : MIROC5 (JPNO2)
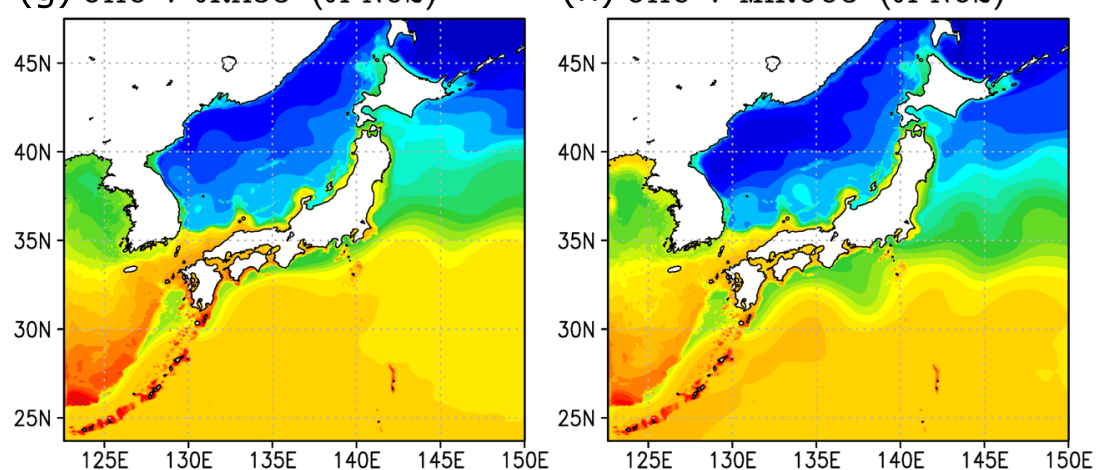

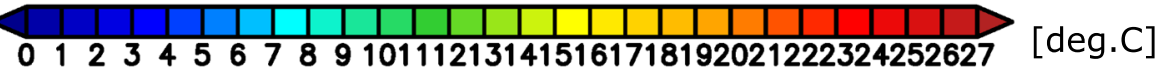

Fig. 3 The 10-year (1996-2005) mean maps of the $\mathrm{OHC}\left({ }^{\circ} \mathrm{C}\right)$ derived by averaging the surface 0-700 $\mathrm{m}$ layer temperature. a FORA-WNP30. The original $\mathbf{b}$ MIROC5 and $\mathbf{c}$ MRI-CGCM3 ocean products. The NP10 results are shown in $\mathbf{d}$ JRA-55, e MIROC5, and $\mathbf{f}$ MRI-CGCM3. The JPN02 results are shown in $\mathbf{g}$ JRA-55, $\mathbf{h}$ MIROC5, and $\mathbf{i}$ MRI-CGCM3. The thick red line overlaid on (a) is the meridional cross section plotted in Fig. 5. The boxes overlaid on (d) are for deriving the area mean OHC analyses plotted in Figs. 4 and 8. The original MIROC5 and MRI-CGCM3 cases of (b) and (c) are regridded to the standard WOA grid

\subsection{Coastal ocean representation and future projections} around Japan

Strait throughflows (e.g., the Straits of Tsushima, Tsugaru, and Soya around the Japan Sea) are important coastal oceanographic metrics around Japan (e.g., Han et al. 2016). Since the original CMIP5 ocean products with $\mathrm{O}(100 \mathrm{~km})$ resolution cannot sufficiently represent the details of these straits, it is necessary to employ the downscaling approach. Figure 9 presents the vertical cross-sections of the potential density and zonal velocity at $129.45^{\circ} \mathrm{E}$ across the Tsushima Strait. As is shown in the ocean reanalysis data (Fig. 9a), the Tsushima Strait has a shallow bottom (less than $200 \mathrm{~m}$ ) and is divided by Tsushima Island, where the Tsushima Warm Current 


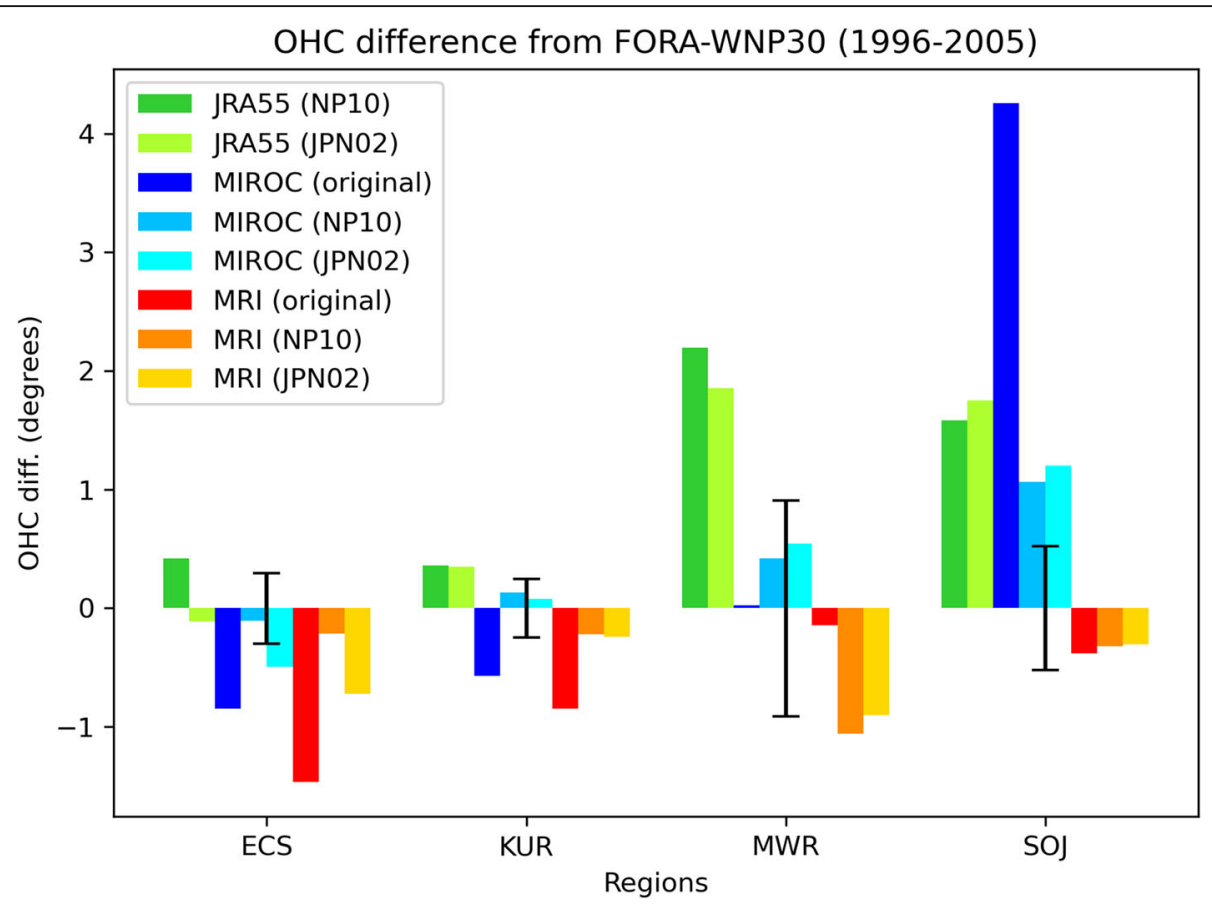

Fig. $4 \mathrm{OHC}$ differences (biases) from the ocean reanalysis (FORA-WNP30) values for four rectangular regions (shown in Fig. 3d), comparing the NP10 and JPN02 results (JRA-55, MIROC5, MRI-CGCM3) and the original CMIP5 results (MIROC5 and MRI-CGCM3) for the historical term (19962005). The error bar in each region denotes the standard deviation of the monthly OHC for the term 1996-2005 from the reanalysis

flows eastward with lighter (warmer) surface water over denser (colder) bottom water (e.g., Isobe et al. 2002). The JPN02 results (Fig. $9 \mathrm{e}-\mathrm{g}$ ) represent this current structure well because the bottom topography of the Tsushima Strait would be reasonably accurate. The current strengths of the southern branch in the NP10 results (Fig. 9b-d) were weaker by more than $10 \mathrm{~cm} \mathrm{~s}^{-1}$ than those of the reanalysis and JPN02 results. Figure 10 presents the vertical cross-sections at $140.55^{\circ} \mathrm{E}$ across the Tsugaru Strait, where the Tsugaru Warm Current flows eastward, as is shown in Fig. 10a. The width of the Tsugaru Strait at the narrowest position is about $20 \mathrm{~km}$. Therefore, the $10-\mathrm{km}$ resolution is apparently insufficient to represent the Tsugaru Warm Current structure. In fact, the current in the $10-\mathrm{km}$ reanalysis and NP10 results (Fig. 10a-d) appeared to be too coarse against the observed structure (e.g., Ito et al. 2003), whereas the JPN02 results (Fig. 10e-g) represented the finer flow structure in the strait. Similar improvements in the strait bathymetry and current structure from the NP10 to the JPN02 were also apparent for the Soya Strait $\left(142^{\circ} \mathrm{E}\right.$, $45.4^{\circ} \mathrm{N}-46^{\circ} \mathrm{N}$ ) that has a width of $40 \mathrm{~km}$ (not shown).

Figure 11a compares the 10-year (1996-2005) mean transport through the Tsushima, Tsugaru, and Soya Straits among the reanalysis, NP10, and JPN02 results. For observational references of the transport through these straits (black bars), we utilized $2.65 \mathrm{~Sv}$ from
Fukudome et al. (2010), 1.5 Sv from Ito et al. (2003), and $0.91 \mathrm{~Sv}$ from Ohshima et al. (2017), respectively. For the Tsushima and Soya Strait transports, while the reanalysis and JRA-55 forced results were closer to the observation, the MIROC5 and MRI-CGCM3 forced results underestimated the transports for both straits. These underestimations would partly come from the surface winds of the MIROC5 and MRI-CGCM3 atmospheres (e.g., Tsujino et al. 2008). It was also found that the underestimated transports in the NP10 were improved in the JPN02 results, probably due to the more realistic representation of the strait bathymetry. For the Tsugaru Strait transport, the three NP10 results indicated the overestimation. The JPN02 results again showed closer transports to the observation, as they included improved horizontal resolution for the Tsugaru Strait. Figure 11b depicts the future impact on the transports for the MRICGCM3 forced results of the JPN02. The RCP8.5 result (2086-2095) suggests increases (+ 0.15 to + $0.2 \mathrm{~Sv}$ ) from the historical result (1996-2005) for the transports through the straits, whereas the changes in the RCP2.6 case were smaller. The future increases in the strait transports in the RCP8.5 case appeared to be opposite to the future decrease in the Kuroshio transport (Fig. 6). These transports (the Kuroshio and the three straits around Japan) should be closely affected by future changes in the surface winds (Fig. 2). Investigation of the details of these 

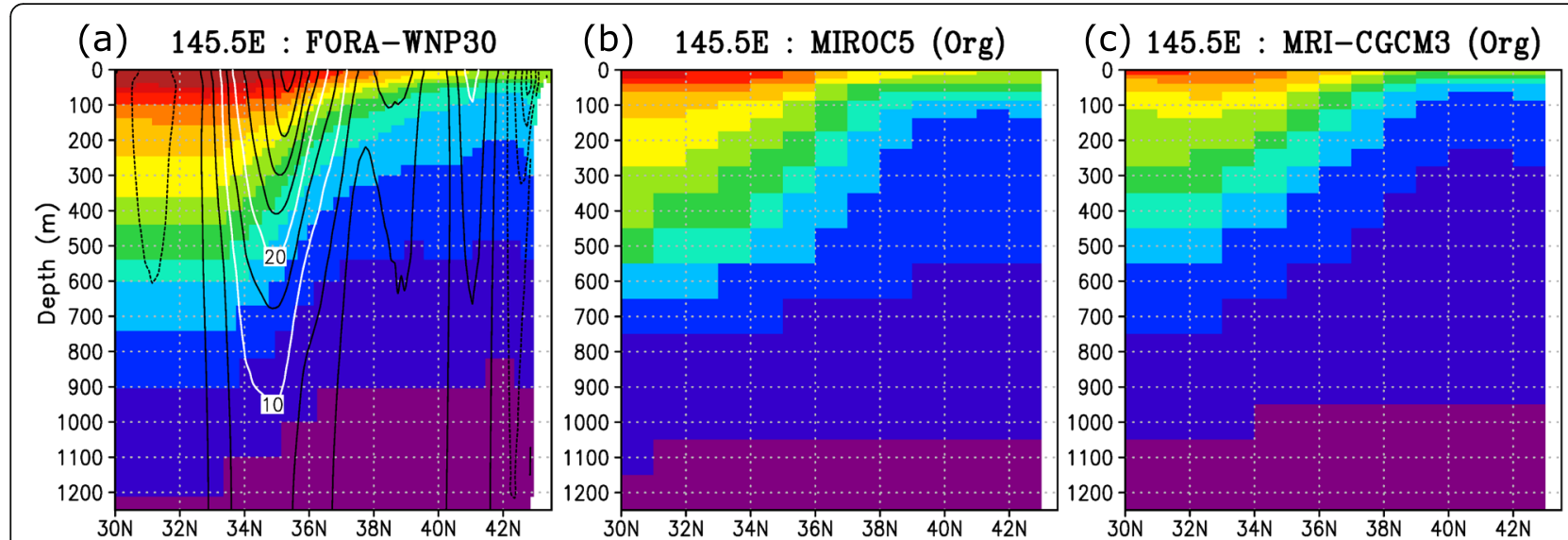

(d) $145.5 \mathrm{E}:$ JRA55 (NP10)
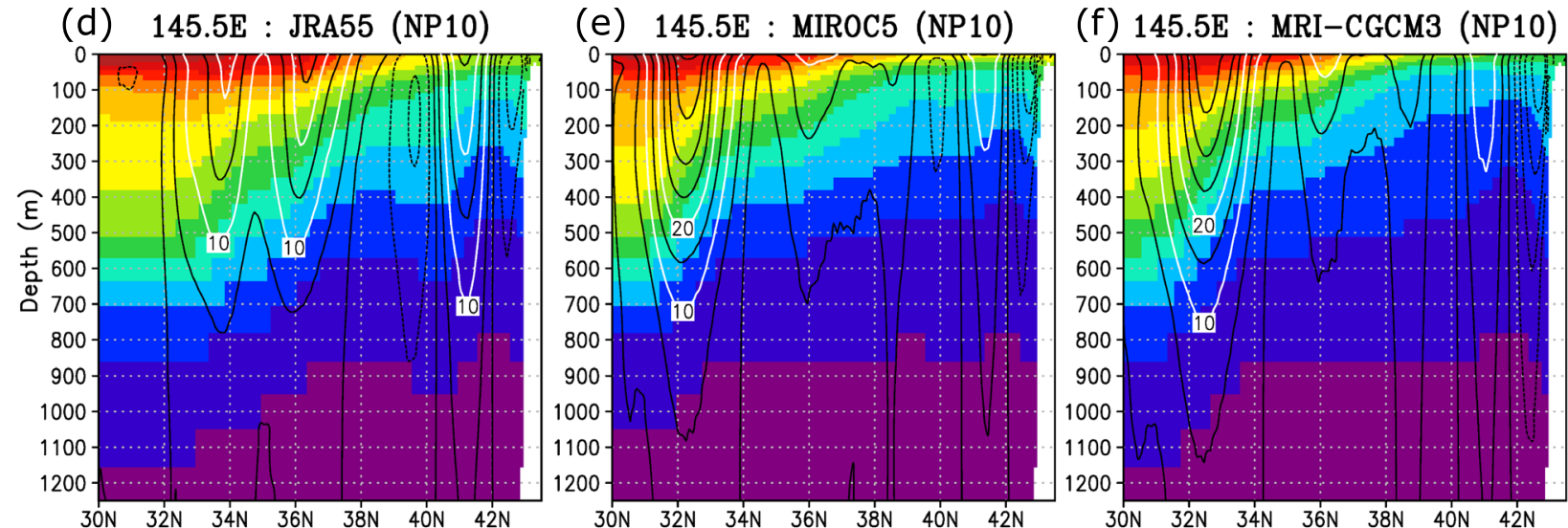

(g) $145.5 \mathrm{E}:$ JRA55 (JPNO2)
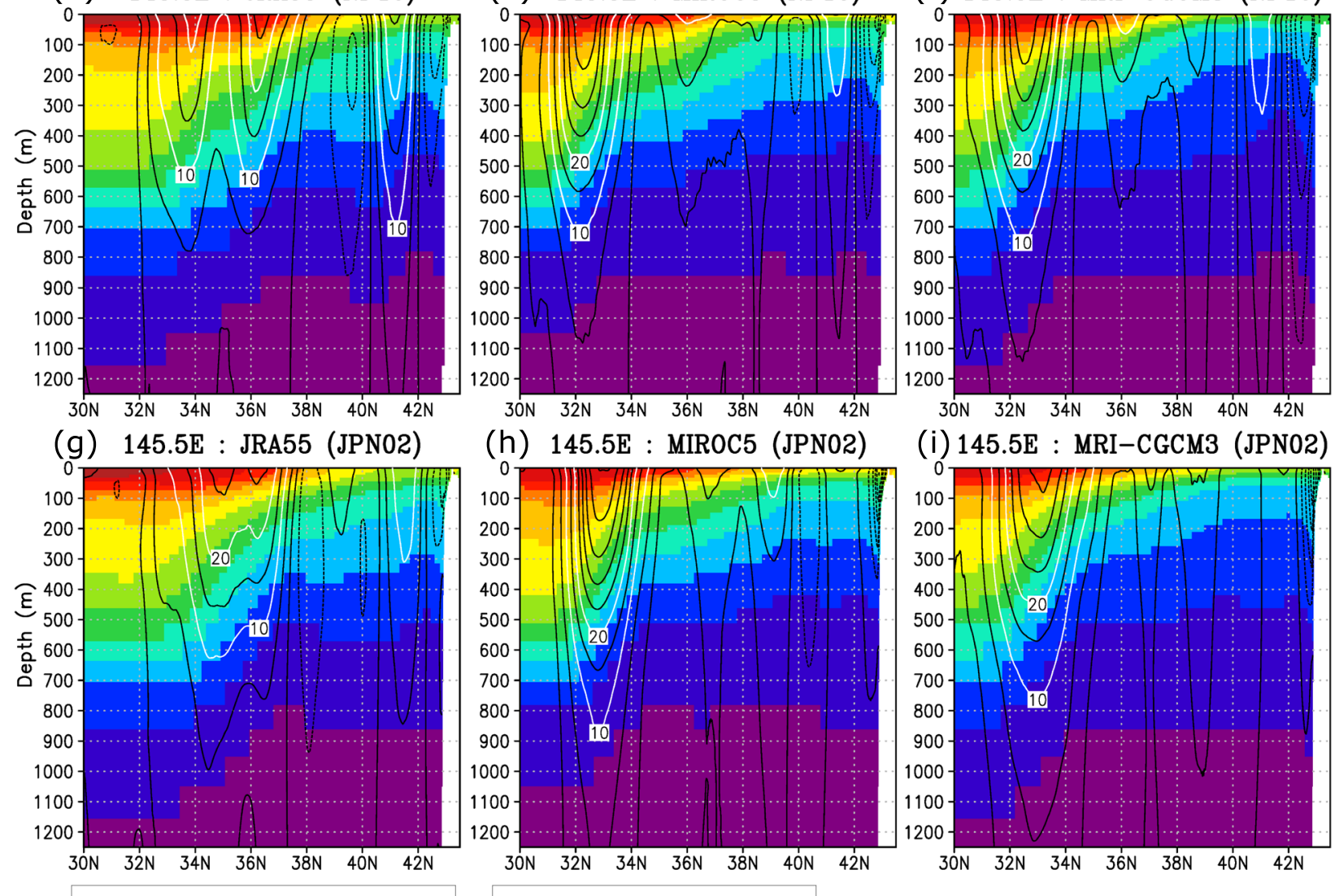

Contours: velocity $(\mathrm{cm} / \mathrm{s})$

(interval: $5 \mathrm{~cm} / \mathrm{s}$ )

(white labeled: $10,20 \mathrm{~cm} / \mathrm{s}$ )

Shades: density $(\mathrm{kg} / \mathrm{m} 3)$

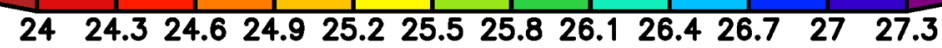

Fig. 5 The 10-year (1996-2005) mean potential density $\left(\mathrm{kg} \mathrm{m}^{-3}\right.$ ) cross-sections along $145.5^{\circ} \mathrm{E}$ from $30^{\circ} \mathrm{N}$ to $43^{\circ} \mathrm{N}$ (see the thick red line in Fig. 3a). a FORA-WNP30. The original b MIROC5 and c MRI-CGCM3 ocean products. The NP10 results are shown in $\mathbf{d}$ JRA-55, e MIROC5, and $\mathbf{f}$ MRICGCM3. The JPNO2 results are shown in $\mathbf{g}$ JRA-55, h MIROC5, and i MRI-CGCM3. The contours in (a) and (d)-(i) denote the zonal velocity (solid, eastward; dotted, westward) and the contour interval $(\mathrm{Cl})$ is $5 \mathrm{~cm} \mathrm{~s}^{-1}$

relationships, however, is beyond the scope of this paper but would be an interesting future research topic.

The reproducibility and variability of the coastal sea level, or SSH, are important targets of coastal applications in the Japanese coastal region. Figure 12 shows the SSH variance from the coastal tide gauge observation data (1997-2005) of the Japan Meteorological Agency (e.g., Sakamoto et al. 2016, 2019), which is the 


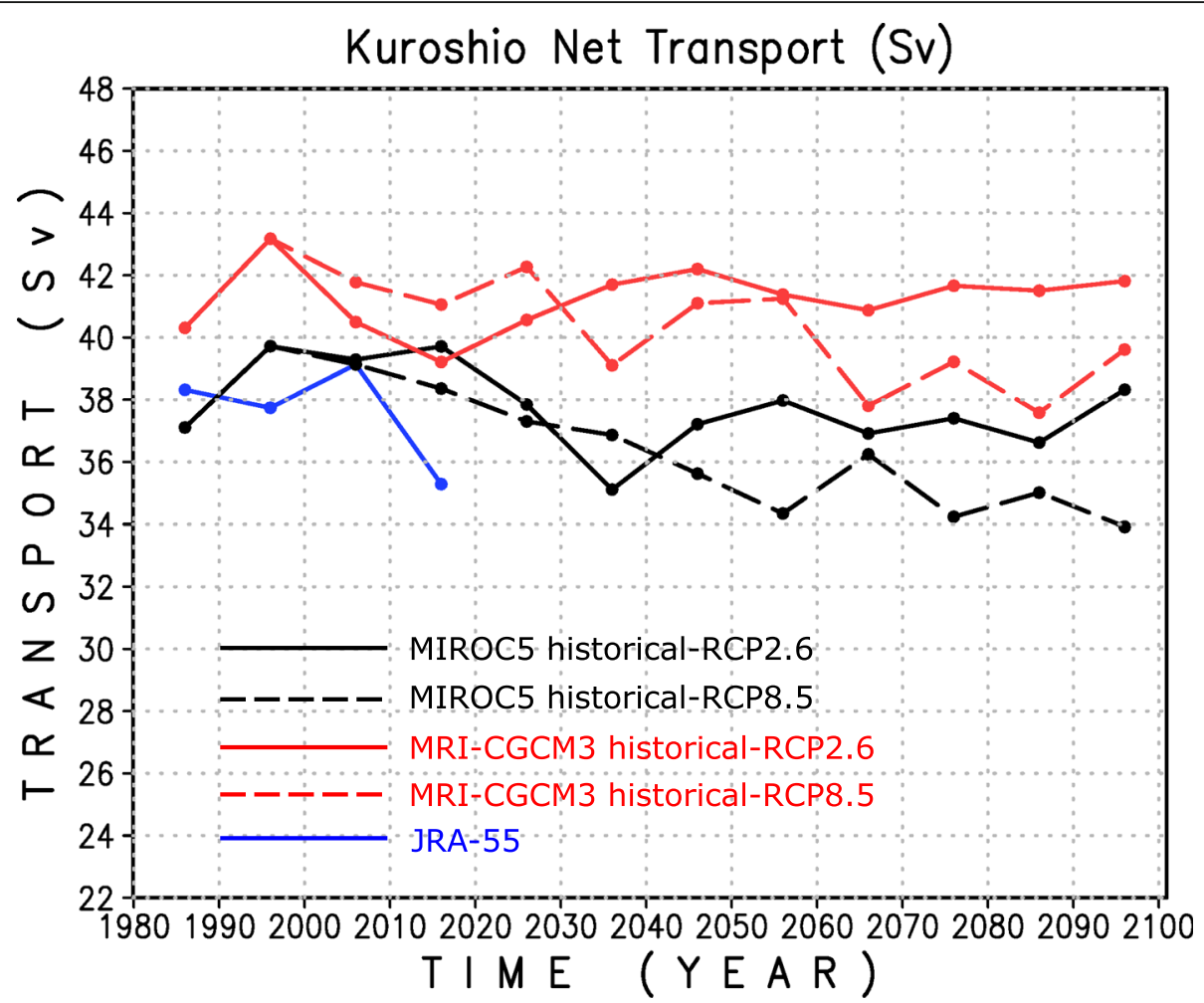

Fig. 6 Time series of the 10-year mean net Kuroshio transport (Sv), estimated from the transport stream function between $\left(26^{\circ} \mathrm{N}, 140^{\circ} \mathrm{E}\right)$ and $\left(34^{\circ}\right.$ $\left.\mathrm{N}, 134^{\circ} \mathrm{E}\right)$ from the NP10 results. Note that the last value of JRA-55 is the 5-year (2011-2015) mean

daily mean data, excluding tidal variation. Using this data, we validated the coastal SSH variance in Japan for the JPN02 results. Figure 13 shows the ratio of the SSH variance from the ocean reanalysis and three JPN02 results against the observation value (Fig. 12). Figure 13a and $\mathrm{b}$ indicates that the SSH variances in the reanalysis and JRA-55 forced result were close to that of the observation (more than 0.7 in many instances, except for Hokkaido Island). In contrast, the MIROC5 and MRICGCM3 forced results (Fig. 13c, d) were generally smaller, i.e., less than 0.6 in most cases, except for Kyushu and part of Shikoku Island. The relatively small
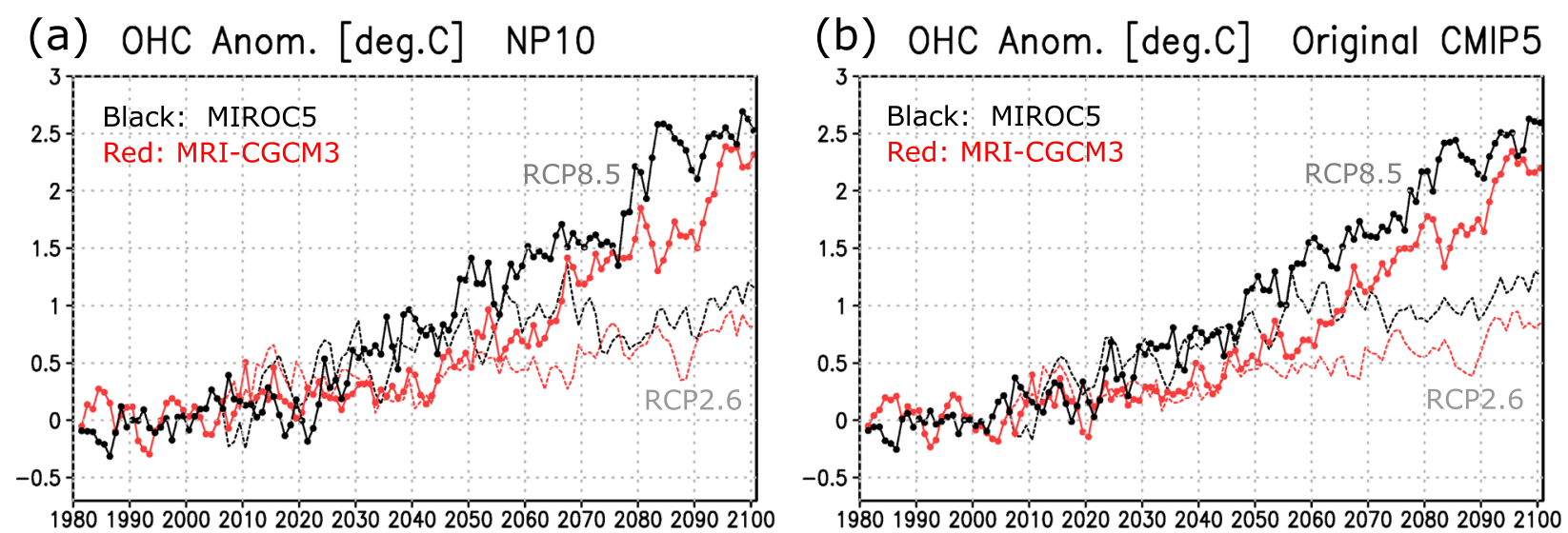

Fig. 7 a Transitions (1981-2100) of the $\mathrm{OHC}$ anomalies $\left({ }^{\circ} \mathrm{C}\right)$ against the $1986-2005$ mean for the area surrounding Japan $\left(123^{\circ} \mathrm{E}-150^{\circ} \mathrm{E}, 24^{\circ} \mathrm{N}-\right.$ $47^{\circ} \mathrm{N}$ ) from the NP10 results. Black, MIROC5; red, MRI-CGCM3; thick solid line, historical + RCP8.5; thin dotted line, RCP2.6. b The same as (a), but using the corresponding original CMIP5 ocean products 


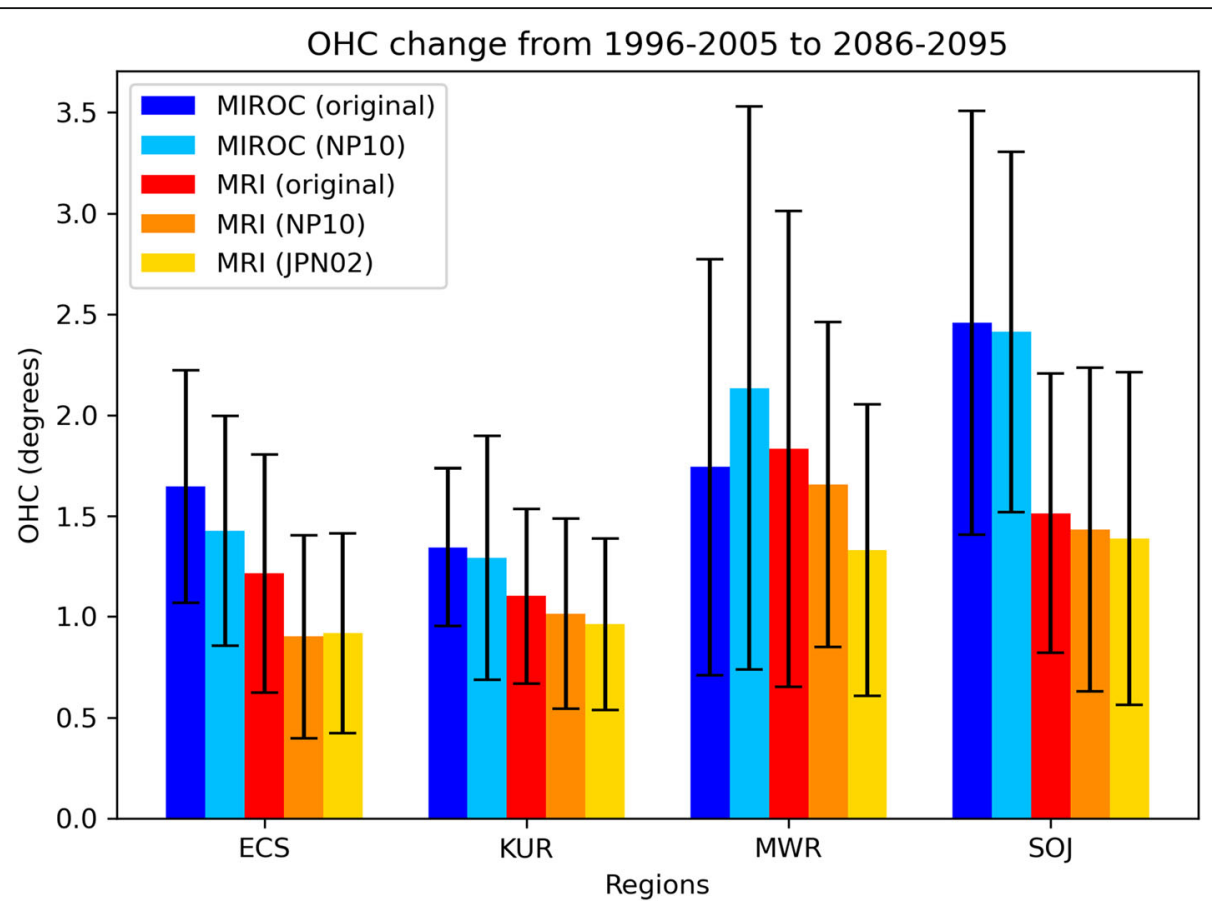

Fig. 8 OHC changes for four rectangular regions (shown in Fig. 3d) from the 1996-2005 mean to the 2086-2095 mean, comparing the NP10, JPN02, and their original products. The box bars denote the average of RCP2.6 and RCP8.5, and the error bars the range from RCP2.6 to RCP8.5. Note that the OHCs for the ECS region are derived from the surface 0-300 $\mathrm{m}$ layer temperature (the others are derived from the surface 0-700 m layer)

amplitude of the SSH variance in the MIROC5 and MRI-CGCM3 forced results could be partly due to the coarse spatial resolution of their atmospheric forcings (see the Section 2).

The SSH variances were higher along the southern coast of Japan, as is shown in Fig. 12, through the effect of the Kuroshio current. However, the higher SSH variances in this coastal area were found to be weak in the MIROC5 and MRI-CGCM3 forced results (Fig. 13c, d) due to the southward shift (bias) of the Kuroshio position (Figs. 3 and 5). Figure 14 shows the $\mathrm{SSH}$ variance at seven points from the southern coast of Japan denoted in Fig. 12, comparing three terms from the MRICGCM3 forced cases and the observation. The apparent eastward reduction and bias of the SSH variance in the historical term (light blue bars) indicate the influence of the southward-shifted position of the Kuroshio. This bias (the weaker SSH variability) would be important for data users interested in its application to the southeastern coast of Japan. Future changes in the SSH variance at the coastal points are indicated by comparing the light blue (historical), blue (RCP2.6), and red (RCP8.5) bars in Fig. 14. In the RCP8.5, the SSH variances were increased on the eastern side against those in the historical term, probably because of the future northward shift of the Kuroshio (Fig. 2). In the RCP2.6, the SSH variances were decreased on the western side, which could also relate to the local change in the Kuroshio path in the future term.

As an example of a coastal phenomenon, we examined the Kuroshio intrusion phenomenon into the bays along the southern coast of Japan. Figure $15 \mathrm{a}-\mathrm{f}$ presents the time series of the daily mean velocity and temperature at a coastal point $\mathrm{P}\left(139.21^{\circ} \mathrm{E}, 35.09^{\circ} \mathrm{N}\right)$ in Sagami Bay (e.g., Fig. 15g) comparing the MRI-CGCM3 forced results from the JPN02 and NP10, and the ocean reanalysis. The observations (e.g., Matsuyama et al. 1999) revealed that an occasional stormy current (called "Kyucho") occurred in Sagami Bay due to the intrusion of the Kuroshio warm water from the east, as indicated by a sudden increase in the southward flow and temperature at point P. In the JPN02 result, the red arrows in Fig. 15a, d corresponded to this phenomenon, with the increased velocity being close to Matsuyama et al.'s (1999) observed value of over $50 \mathrm{~cm} \mathrm{~s}^{-1}$. Figure $15 \mathrm{~g}$ presents the velocity map on the date of the sudden increase. The anticlockwise coastal flow in Sagami Bay was consistent with Matsuyama et al.'s (1999) description. Although such sudden increase was also found in the $10-\mathrm{km}$ reanalysis and NP10 results (the red arrows in Fig. 15b, c, e, f), it seemed to be much weaker than the observed value and should not have been reflected by the real 


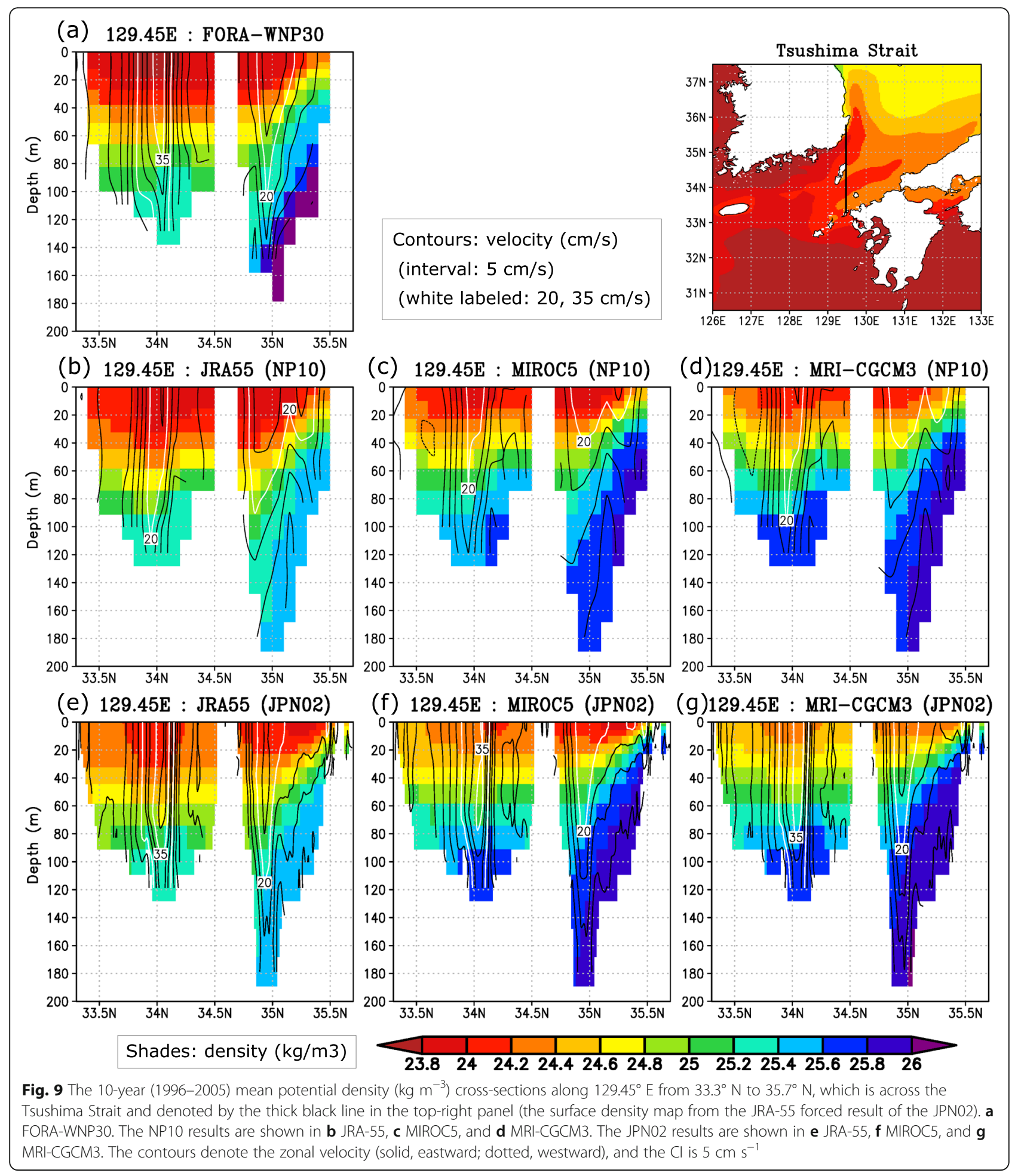

"Kyucho" mechanism. In fact, the corresponding velocity maps at the event times (Fig. 15h, i) imply that the lack of horizontal resolution and unrealistic coastal geometry led to insufficient representations of the Kuroshio warm water intrusion into Sagami Bay.
Note that the apparent close timing of the increase between these data (Fig. 15a-c) is not essential, as the "Kyucho" is a stochastic event.

The sudden increase at P in Sagami Bay for the historical (1996-2005) and future RCP2.6/RCP8.5 (2086- 


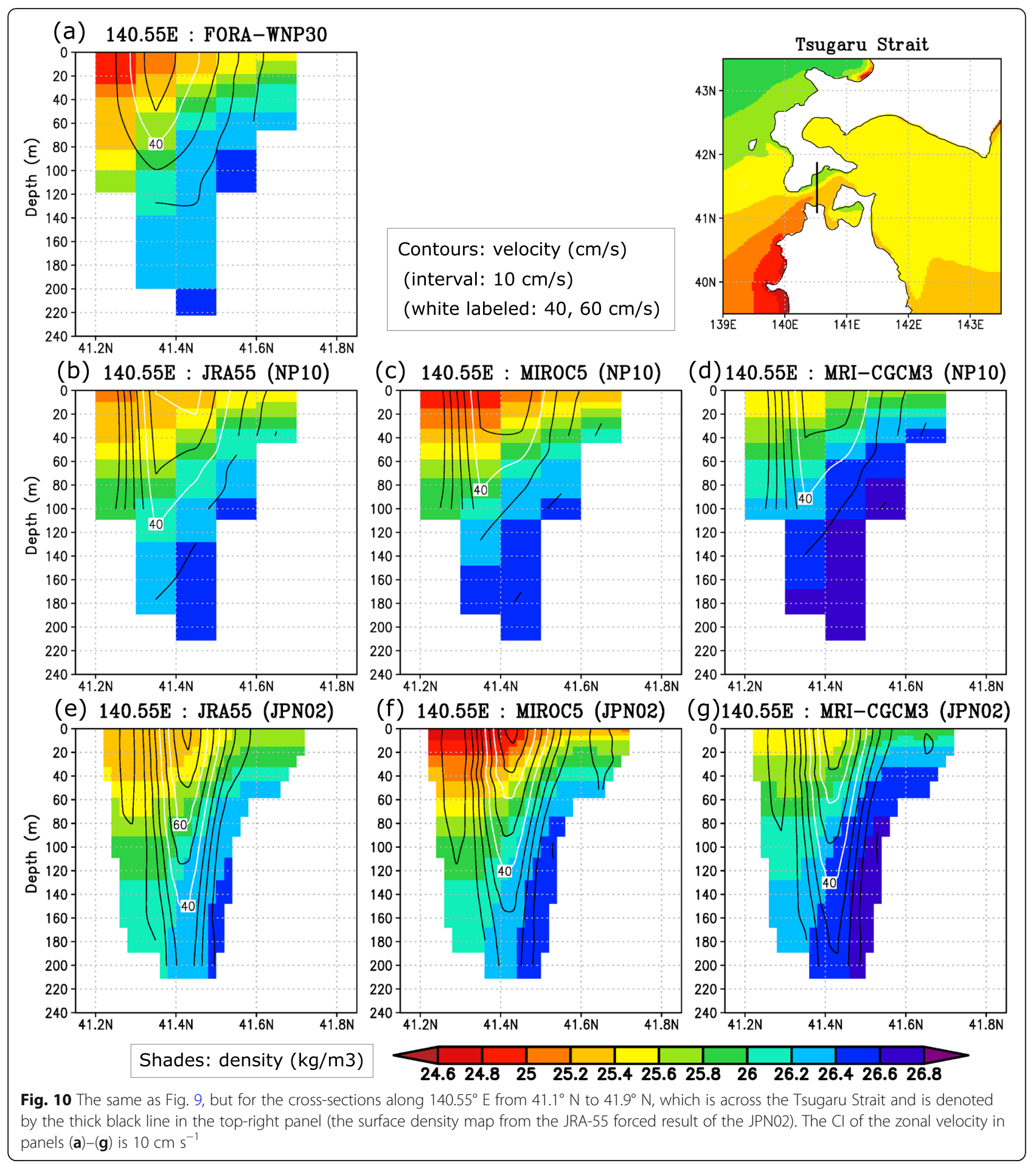

2095) runs was statistically evaluated in Table 6, where the 10-year frequencies of sudden meridional velocity increase were counted based on the threshold velocity values. Given the $\mathrm{SD}$ of the meridional velocity at $\mathrm{P}$, we used the threshold meridional velocity value of $-30 \mathrm{~cm}$ $\mathrm{s}^{-1}$ for the JPN02 results and $-13 \mathrm{~cm} \mathrm{~s}^{-1}$ for the NP10 result and reanalysis. Consequently, the 10-year frequency of the occurrence in the historical term (1996-2005) for the JPN02 result was 38, and the frequency was increased by $10-20 \%$ in both future projection cases ( 42 for RCP8.5 and 46 for RCP2.6, in 20862095) accompanied by the $7-10 \%$ increases in the velocity variabilities (SD in Table 6). The future change in the Kuroshio path and KE latitude in these RCP cases 


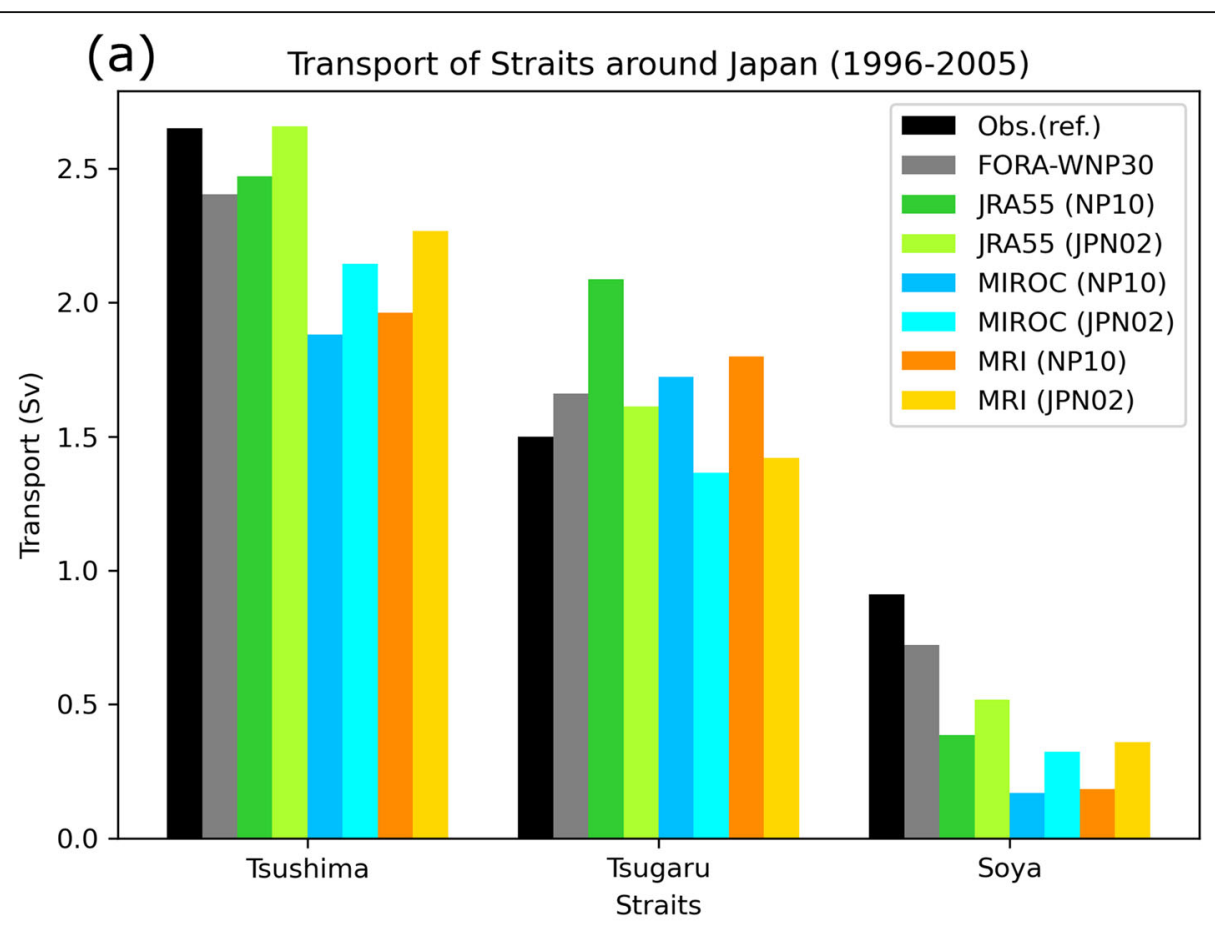

(b) Transport of Straits around Japan (JPN02)

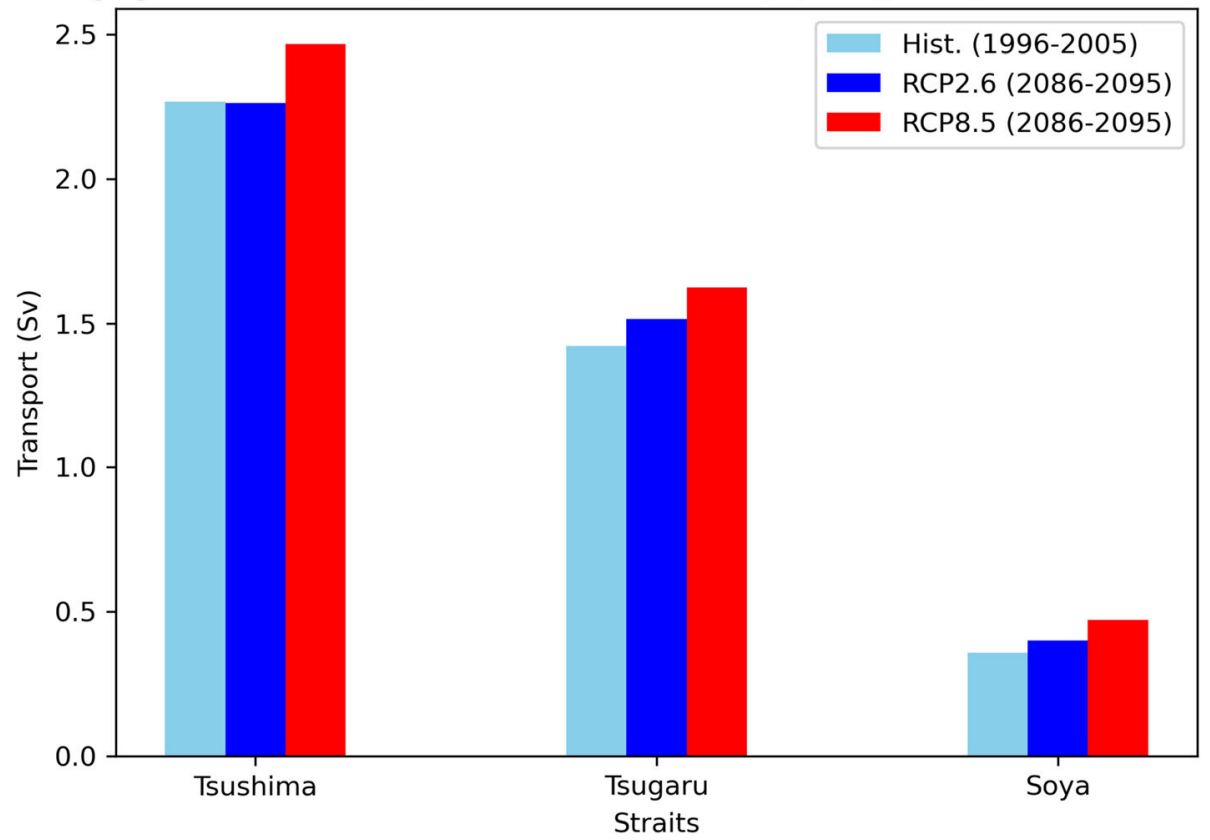

Fig. 11 a The 10-year (1996-2005) mean transports (Sv) through the Tsushima, Tsugaru, and Soya Straits from the JPN02, NP10, and FORAWNP30 (colored bars). The observational reference values (black bars) are 2.65 Sv from Fukudome et al. (2010) for the Tsushima Strait, 1.5 Sv from Ito et al. (2003) for the Tsugaru Strait, and 0.91 Sv from Ohshima et al. (2017) for the Soya Strait. b Same as (a), but comparing the historical (1996-2005), RCP2.6 (2086-2095), and RCP8.5 (2086-2095) cases of the MRI-CGCM3 forced results of the JPN02

may have affected these "Kyucho" frequency and intensity increases; however, a more detailed analysis into the future Kuroshio impacts would be needed to clarify the relationship with this coastal event. Note that in the $10-\mathrm{km}$ products, the velocity variances and event frequencies were much weaker and the mean velocities were opposite to the JPN02 cases (Table 6), implying that the "Kyucho" phenomenon was not properly represented with the $10-\mathrm{km}$ horizontal resolution. 


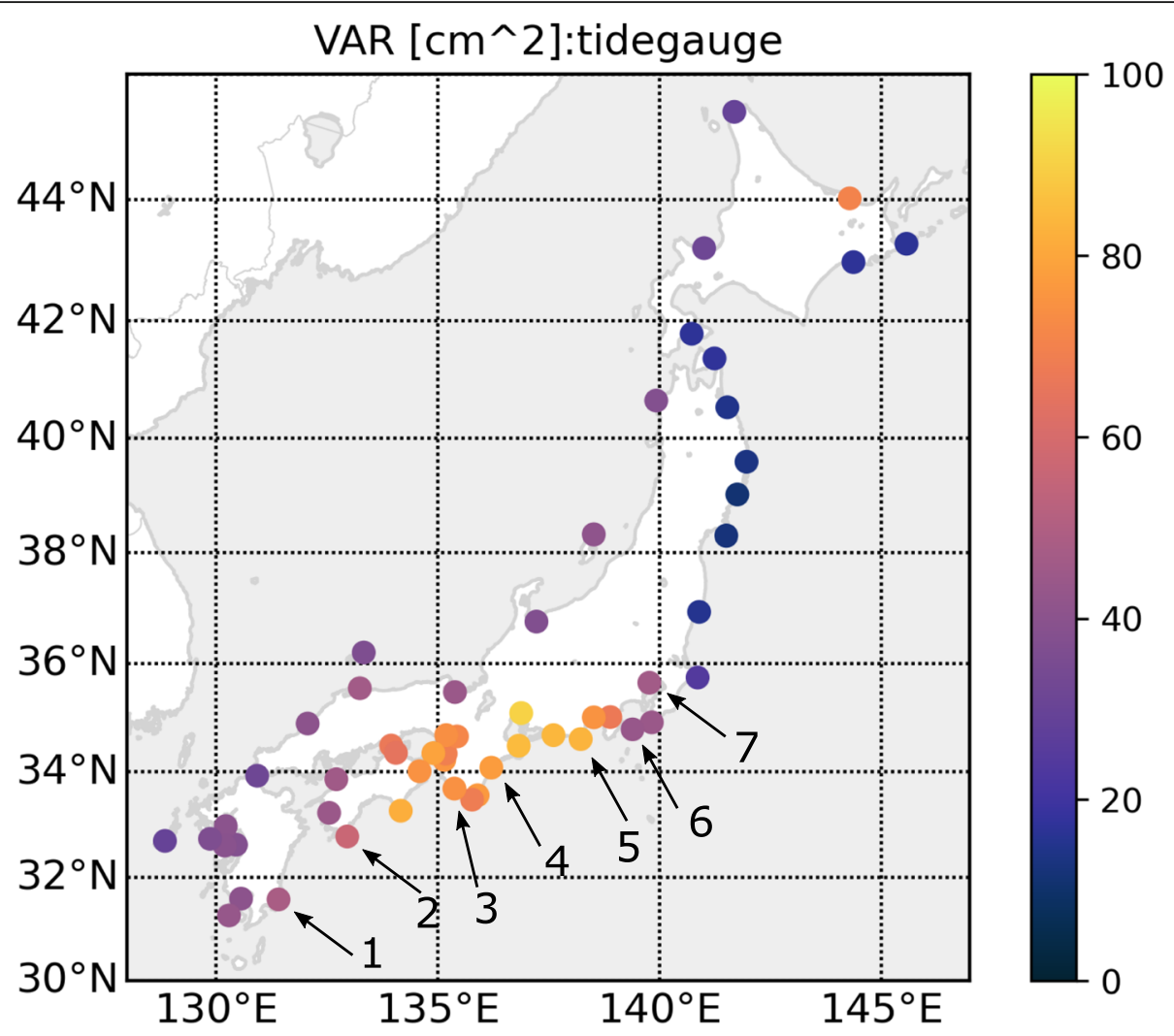

Fig. 12 Variances $\left(\mathrm{cm}^{2}\right)$ in the sea level along the coast of Japan denoted by colored circles, from the coastal tide gauge observation data (19972005) by the Japan Meteorological Agency (JMA), which is the daily mean data, excluding tidal variation. The calculation of variance was based on a daily anomaly from the daily climatology (and so the effect of the seasonal cycle was excluded). The seven points denoted by the arrows are used in Fig. 14

In summary, the JPN02 was used to reasonably represent the coastal currents and finer-scale structures (e.g., strait throughflows and transports around Japan and the Kuroshio intrusion phenomenon in the Japanese coastal region) over the historical term due to the $\mathrm{O}(2 \mathrm{~km})$ resolution with finer coastal geometry. The coastal sea level variance in the MIROC5 and MRICGCM3 forced results of the JPN02 was smaller than that of the observation and the JRA-55 forced results, especially along the southern coast of Japan, in which the effect of the Kuroshio bias was large. Possible future changes in the coastal flows (the strait throughflows and "Kyucho" phenomenon) and SSH variance were examined, and it was suggested that these were strongly affected by the larger-scale Kuroshio properties (e.g., the axis position). These are important points to be taken into account by users of the FORP data. Note that the future impact analyses using the JPN02 (Figs. 11 and 14 and Table 6) were based on only one model (i.e., the MRI-CGCM3) projection data, and so multi-model ensemble downscaling projections with the JPN02 are needed to achieve greater scientific validity in future research.

\section{Discussion and Conclusions}

In this study, we developed the FORP datasets via the dynamical downscaling using the MIROC5 and MRI-CGCM3 (from CMIP5) atmospheric forcings, comprising the NPO dataset with a $10-\mathrm{km}$ resolution and the regional dataset surrounding Japan with a 2-km resolution, i.e., FORP-NP10 and FORP-JPN02. The datasets were to provide a set of likely future NPO and Japanese coastal ocean states within the scope of the SI-CAT project, i.e., to assist stakeholders in developing an adaptation plan for the Japanese coast. For crossvalidation purposes, the FORP datasets included historical experiments using the JRA-55 atmospheric reanalysis forcing and shared some basic specifications with the ocean reanalysis data FORA-WNP30. The usability of these reference data for evaluating various biases of the model ocean states is an important feature of these datasets.

Both the FORP-NP10 and FORP-JPN02 data were found to reproduce the primary flow structures around Japan, in particular the Kuroshio and Oyashio currents with their frontal and jet structures, which had proved difficult to evaluate using the low-resolution products of the original CMIP5 models (Figs. 3 and 5). The Kuroshio transports were reasonable, and the KE positions 

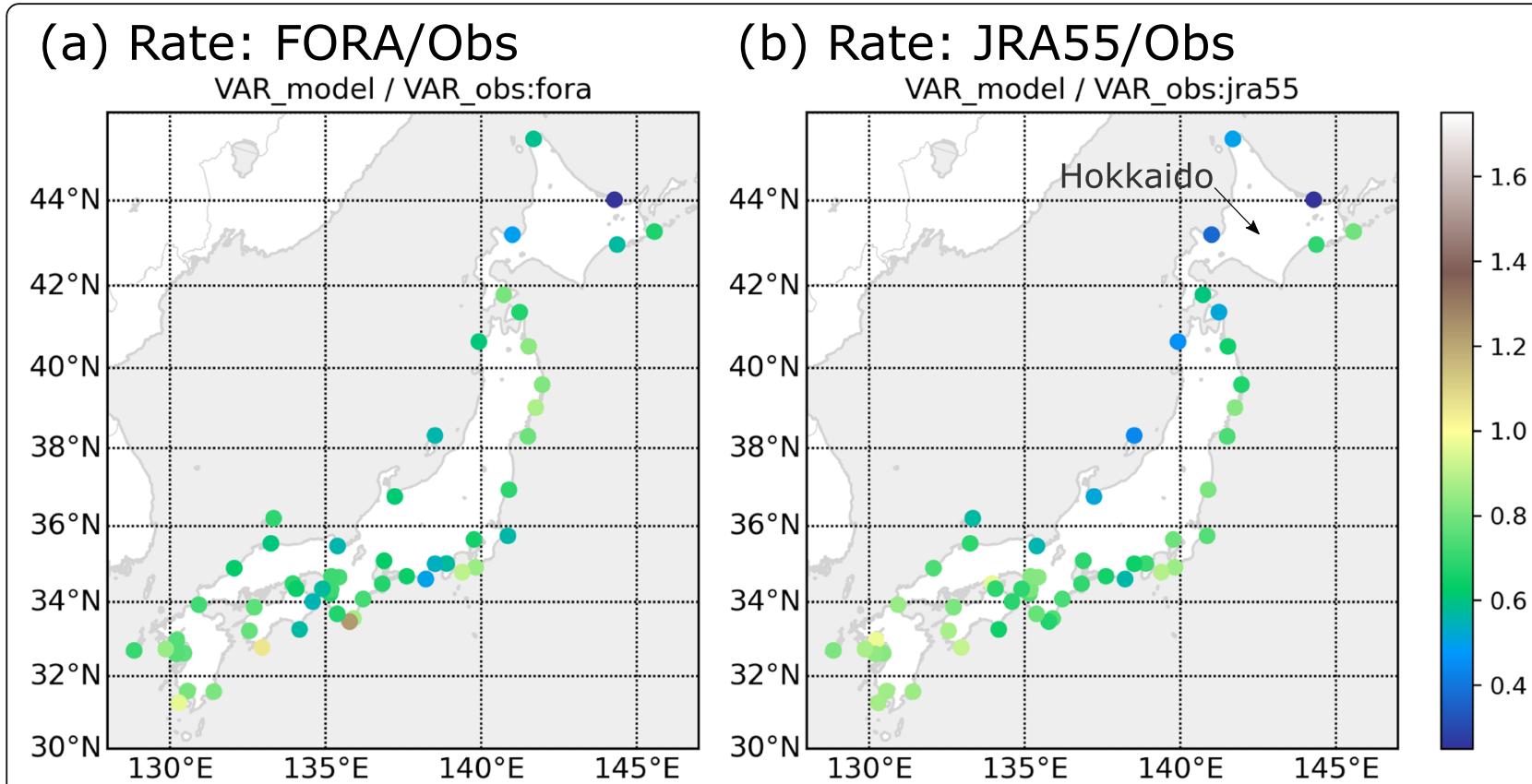

\section{(c) Rate: MIROC/Obs}

VAR_model / VAR_obs:miroc

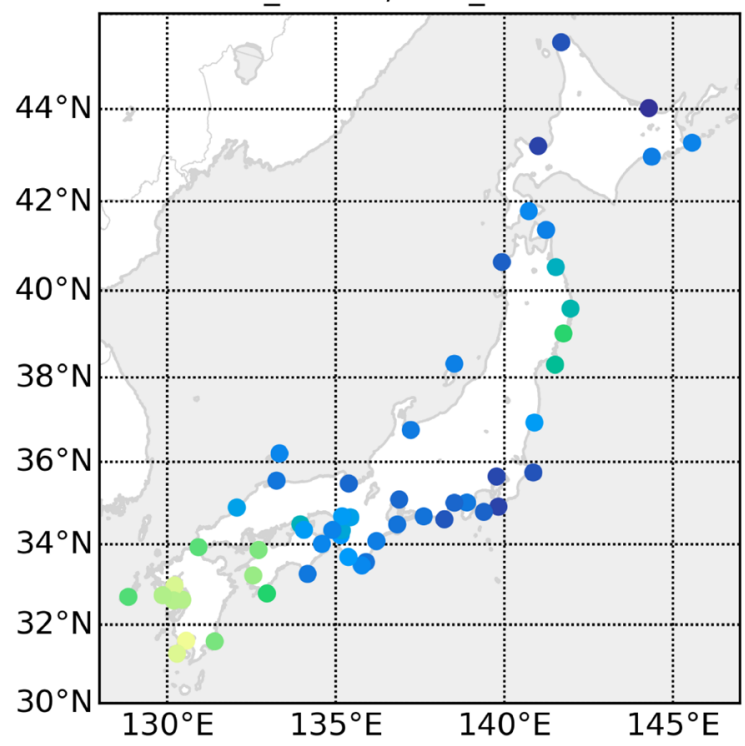

(d) Rate: MRI/Obs

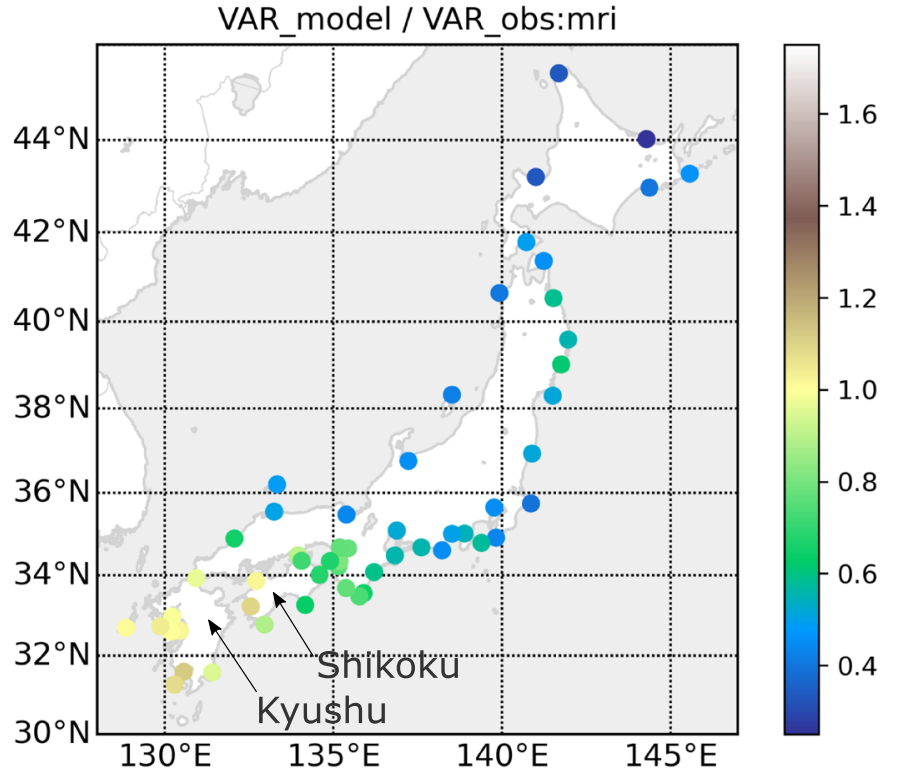

Fig. 13 Ratio of the 10-year (1996-2005) mean SSH variance against the observed value (Fig. 12) along the coast of Japan for a FORA-WNP30 and the JPN02 results of $\mathbf{b}$ JRA-55, $\mathbf{c}$ MIROC5, and $\mathbf{d}$ MRI-CGCM3, which are denoted by colored circles. The calculation of variance was based on a daily anomaly from the daily climatology (thus, the effect of the seasonal cycle was excluded)

exhibited a southward-shifted bias (about $3^{\circ}$ ) in the historical run results (Figs. 3, 5, and 6) consistent with the STSF analysis of each set of atmospheric data (Fig. 2). The FORP-JPN02 data further represented the finer flow structures and transports along the coasts, including the strait throughflows around the Japan Sea (Figs. 9, 10 and 11). The Kuroshio water intrusion into the Japanese coastal region (such as the "Kyucho" phenomenon) was an example of the improved coastal representation in the FORP-JPN02
(Fig. 15), which was difficult to represent at $\mathrm{O}(100 \mathrm{~km})$ to $\mathrm{O}(10 \mathrm{~km})$ resolutions. The $\mathrm{SSH}$ variance along the Japanese coast from the MIROC5 and MRI-CGCM3 forced products of the FORP-JPN02 was smaller than that from the tide gauge observation (Figs. 12, 13, and 14), possibly due to the coarse resolution of their atmospheric forcings. The FORP data reproduced the surface thermal structure with reducing the temperature biases observed in their original (CMIP5) data, while there were some substantial biases in the 


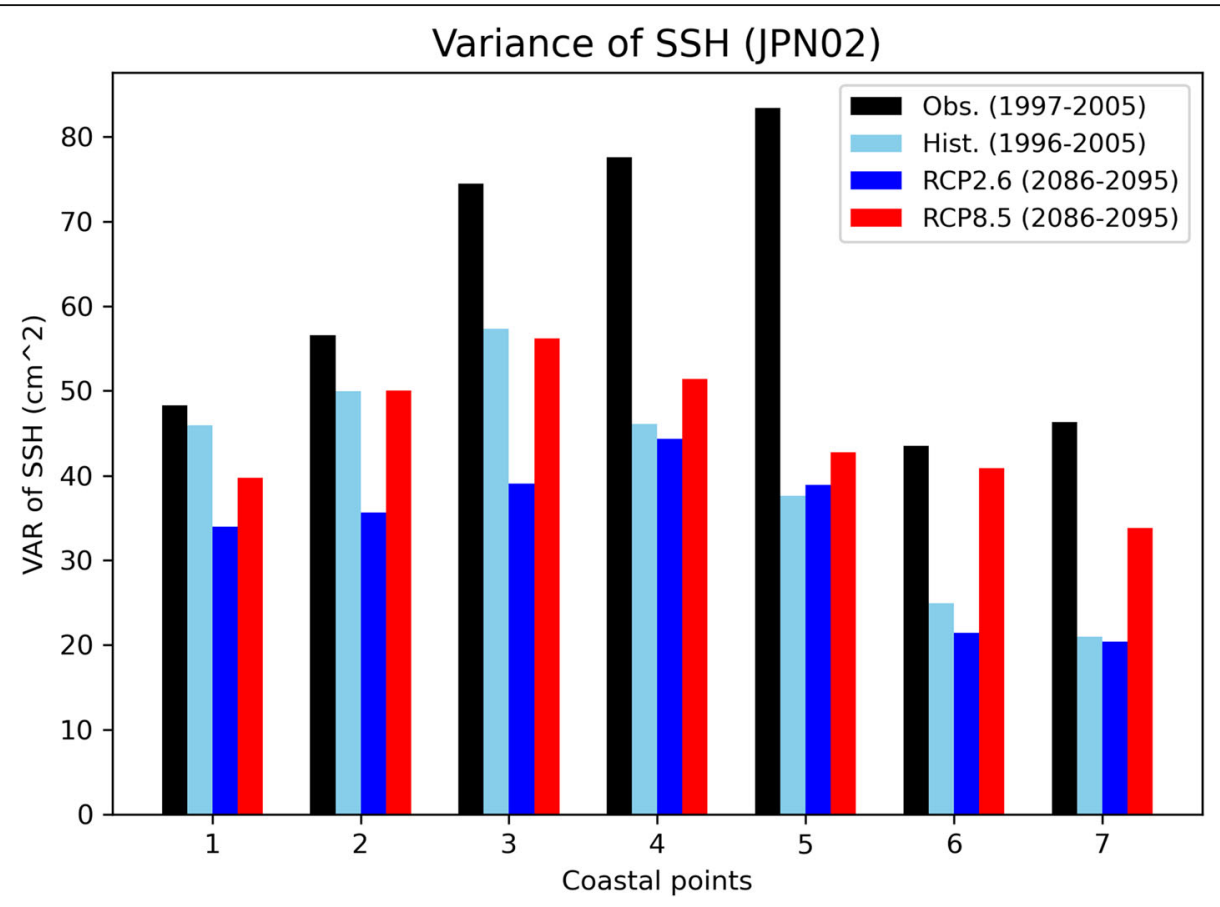

Fig. 14 SSH variance $\left(\mathrm{cm}^{2}\right)$ at seven coastal points along the southern coast of Japan shown in Fig. 12 comparing the historical (1996-2005), RCP2.6 (2086-2095), and RCP8.5 (2086-2095) cases from the MRI-CGCM3 forced results of the JPN02 and the JMA observation (1997-2005)

marginal and northern mixed water regions in both the FORP-NP10 and FORP-JPN02 products (Figs. 3 and 4). The future climate change responses of the surface $\mathrm{OHC}$ around Japan were generally consistent among the FORP-NP10, FORP-JPN02, and their corresponding original data (Figs. 7 and 8).

Based on these assessments, the quality of the FORP dataset is sufficient for use in climate change adaptation studies for the Japanese coastal region. On the other hand, FORP data users should be mindful of the various biases noted above, i.e., regional $\mathrm{OHC}$ biases, smaller variability biases in the coastal $\mathrm{SSH}$, and the southern shift of the Kuroshio position. In particular, the effect of the Kuroshio position bias is important because it would strongly affect future impact analyses of the southern coastal region of Japan (e.g., Fig. 14). Improving upon this is a planned future task of ours.

Future changes in the mean sea levels along the coast are an important target parameter with respect to climate change adaptation issues in Japan. As the present ocean models are volume-conservative and do not explicitly include volume change by thermal expansion and freshwater inputs (e.g., meltwater from glaciers and ice sheets), the future sea level changes in the model provide the local effect of seawater redistribution via ocean circulation due to momentum, heat, and salinity fluxes. The global effects of thermal expansion and freshwater inputs should be assessed on the basis of the original CMIP5 global models and other independent sources (e.g., IPCC SROCC; see
Oppenheimer et al. 2019). The sum of the local effects in the present model and the global effects from external sources can offer an approximate evaluation of future sea level changes along the Japanese coast.

The ensemble of future projections in this study focused on two climate models (MIROC5 and MRICCGM3) from the CMIP5 and featured two scenarios (RCP2.6 and RCP8.5). However, an increase in the ensemble number using more CMIP5 atmospheric forcings is required to evaluate the variance and uncertainty of future projections with greater reliability. In this study, the lateral boundary of the temperature/salinity in the NP10 model was restored to that of the WOA climatology. For the RCP8.5 scenario runs (i.e., under strong global warming scenarios), this lateral boundary setting caused artificial cooling of the surface layer near the southern lateral boundaries of the NP10 model in the future projected fields. Future information on ocean temperature/salinity changes from each CMIP5 model should also be reflected in the lateral boundaries of the NP10 to avoid this artificial cooling and extend the applicability of the FORPNP10 dataset. This is our next task, and a portion of the preliminary results of this can be found in the work of Nishikawa et al. (2020). The present JPN02 model did not include tidal and surface pressure effects, partly due to the computational costs of long-term integration. As these processes are important for further applications in coastal problems (e.g., Sakamoto et al. 2019), these effects should be introduced in future studies. 


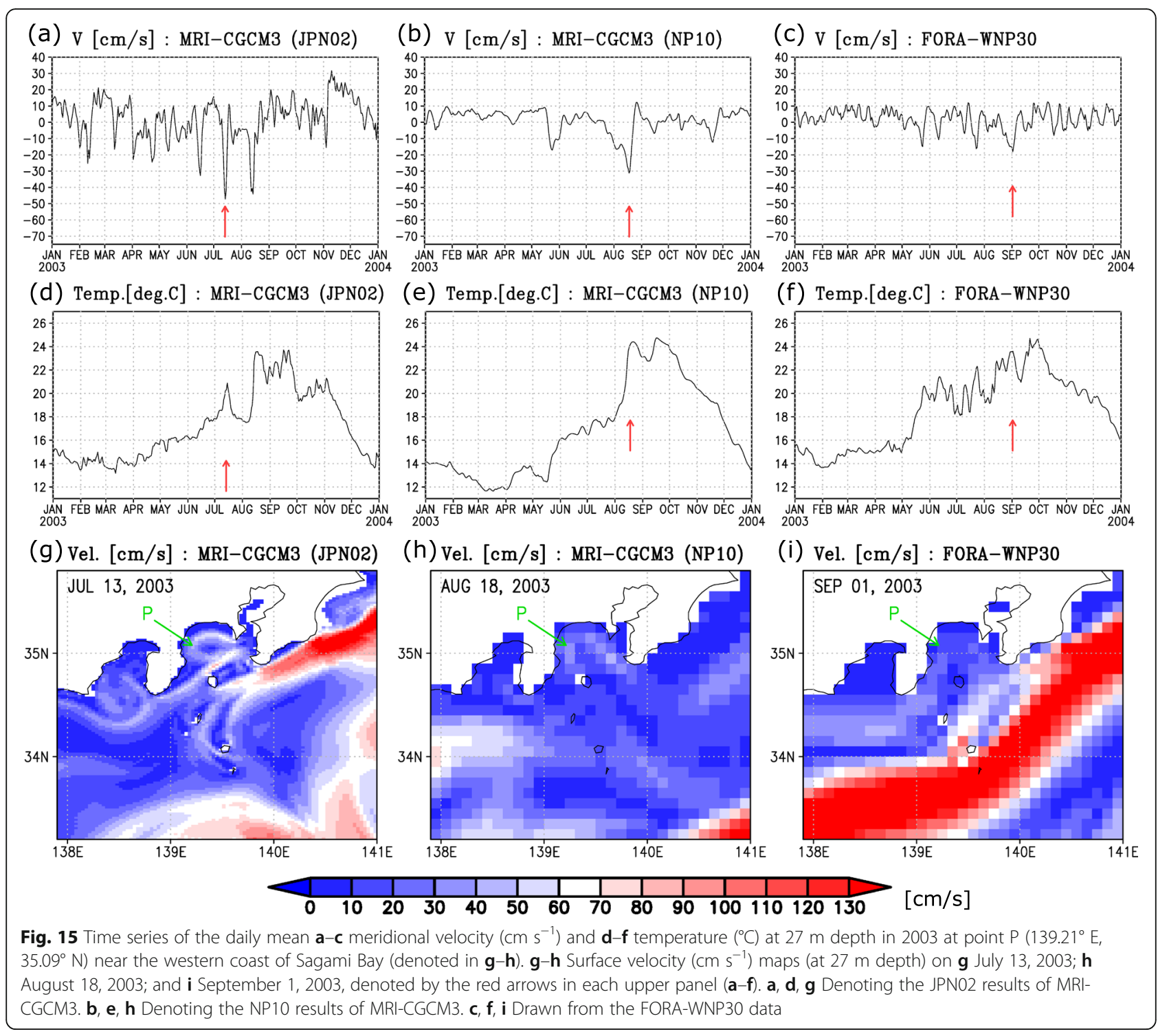

Table 6 Statistics of the meridional velocity $\left(\mathrm{cm} \mathrm{s}^{-1}\right)$ and the sudden increase events ("Kyucho" events) at P in Sagami Bay. "Average" and "SD" denote the 10-year average and standard deviation of the meridional velocity at P, respectively. The 10-year "Frequency" of the "Kyucho" events at $P$ in each case was evaluated based on the "Threshold" velocity value $\left(-30 \mathrm{~cm} \mathrm{~s}^{-1}\right.$ or $\left.-13 \mathrm{~cm} \mathrm{~s}^{-1}\right)$

\begin{tabular}{llllll}
\hline Model/Data & Cases and analysis terms & SD $\left(\mathbf{c m ~ s}^{\mathbf{- 1}}\right)$ & Average $\left(\mathbf{c m ~ s}^{\mathbf{- 1}}\right)$ & Frequency & Threshold $\left(\mathbf{c m ~ s}^{\mathbf{- 1}}\right)$ \\
\hline JPN02 & MRI-CGCM3 historical (1996-2005) & 13.3 & -1.51 & 38 & -30 \\
& MRI-CGCM3 RCP2.6 (2086-2095) & 14.7 & -2.87 & 46 & -30 \\
& MRI-CGCM3 RCP8.5 (2086-2095) & 14.2 & -1.77 & 42 & -30 \\
NP10 & MRI-CGCM3 historical (1996-2005) & 6.49 & 1.38 & 22 & -13 \\
Reanalysis (10 km) & FORA-WNP30 (1996-2005) & 5.46 & 1.56 & 19 & -13 \\
\hline
\end{tabular}




\section{Acknowledgements}

We are grateful to Dr. H. Igarashi for preparing the JRA-55 data, and K. Goto and K. Sakauchi for their assistance in carrying out various numerical experiments on the supercomputer, Earth Simulator, at JAMSTEC. The constructive comments from Dr. T. Suzuki and two anonymous reviewers greatly helped in improving an early version of the manuscript. We also thank Enago (www. enago.jp) for the English language review.

\section{Authors' contributions}

SN developed the model system, designed and conducted the experiments, analyzed the data, and drafted the paper. TW developed the forcing data and model system, designed the experiments, analyzed the data, and drafted the paper. $\mathrm{HI}$ analyzed the data and produced some figures. KS supported the development of the model system, analyzed the data and produced some figures. YT supported the development of the forcing data. HT supported the development of the model system. GY and MK supported the model validation and the data analysis. $\mathrm{Yl}$ proposed the topic and led the SI-CAT project. All authors read and approved the final manuscript.

\section{Funding}

TW was supported partially by the Nansen Center (NERSC) basic funding. This study was supported by the Social Implementation Program on Climate Change Adaptation Technology (SI-CAT: grant no. JPMXD0715667163) and the Integrated Research Program for Advancing Climate Models (TOUGOU: grant no. JPMXD0717935561) sponsored by the Ministry of Education, Culture, Sports, Science and Technology of Japan.

\section{Availability of data and materials}

The FORP datasets produced in this study are available from the DIAS website (http://www.diasjp.net/en/). The ocean reanalysis dataset, FORAWNP30, is available from the following web site: http://www.godac.jamstec. go.jp/fora/e/index.html.

\section{Competing interests}

The authors declare that they have no competing interest.

\section{Author details}

1Japan Agency for Marine-Earth Science and Technology, 3173-25 Showa-machi, Kanazawa-ku, Yokohama 236-0001, Japan. ${ }^{2}$ The Nansen Center, Bergen, Norway. ${ }^{3}$ Bjerknes Centre for Climate Research, Bergen, Norway. ${ }^{4}$ Meteorological Research Institute, Japan Meteorological Agency, Tsukuba, Japan.

Received: 5 January 2020 Accepted: 10 December 2020 Published online: 14 January 2021

\section{References}

Alexander MA, Scott JD, Friedland KD, Mills KE, Nye JA, Pershing AJ, Thoma AC (2018) Projected sea surface temperatures over the 21st century: changes in the mean, variability and extremes for large marine ecosystem regions of Northern Oceans. Elem Sci Anth 6:9. https://doi.org/10.1525/elementa.191

Alexander MA, Shin SI, Scott JD, Curchitser E, Stock C (2020) The response of the Northwest Atlantic Ocean to climate change. J Clim 33:405-428. https://doi. org/10.1175/JCLI-D-19-0117.1

Aoki K, Kutsuwada K (2008) Verification of the wind-driven transport in the North Pacific subtropical gyre using gridded wind-stress products. J Oceanogr 64: $49-60$

Fukudome Kl, Yoon JH, Ostrovskii A, Takikawa T (2010) Seasonal volume transport variation in the Tsushima Warm Current through the Tsushima Straits from 10 years of ADCP observations. J Oceanogr 66:539-551. https://doi.org/10. 1007/s10872-010-0045-5

Han S, Hirose N, Usui N, Miyazawa Y (2016) Multi-model ensemble estimation of volume transport through the straits of the East/Japan Sea. Ocean Dyn 66: 59-76. https://doi.org/10.1007/s10236-015-0896-9

Hermann AJ, Gibson GA, Bond NA, Curchitser EN, Hedstrom K, Cheng W, Wang M, Cokelet ED, Stabeno PJ, Aydin K (2016) Projected future biophysical states of the Bering Sea. Deep-Sea Res II 134:30-47

Hermans THJ, Tinker J, Palmer MD, Katsman CA, Vermeersen BLA, Slangen ABA (2020) Improving sea-level projections on the Northwestern European shelf using dynamical downscaling. Clim Dyn 54:1987-2011
Imawaki S, Uchida H, Ichikawa H, Fukasawa M, Umatani S, the ASUKA Group (2001) Satellite altimeter monitoring the Kuroshio transport south of Japan. Geophys Res Lett 28:17-20

IPCC (2013) In: Stocker TF, Qin D, Plattner G-K, Tignor M, Allen SK, Boschung J, Nauels A, Xia Y, Bex V, Midgley PM (eds) Climate Change 2013: The physical science basis. Contribution of Working Group I to the Fifth Assessment Report of the Intergovernmental Panel on Climate Change. Cambridge University Press, Cambridge and New York, p 1535

IPCC (2014) In: Core Writing Team, Pachauri RK, Meyer LA (eds) Climate change 2014: synthesis report. Contribution of Working Groups I, II and III to the Fifth Assessment Report of the Intergovernmental Panel on Climate Change. IPCC, Geneva, p 151

Isobe A, Ando M, Watanabe T, Senjyu T, Sugihara S, Manda A (2002) Freshwater and temperature transports through the Tsushima-Korea Straits. J Geophys Res 107:3065. https://doi.org/10.1029/2000JC000702

Ito T, Togawa O, Ohnishi M, Isoda Y, Nakayama T, Shima S, Kuroda H, Iwahashi M, Sato C (2003) Variation of velocity and volume transport of the Tsugaru Warm Current in the winter of 1999-2000. Geophys Res Lett 30(13):16781681. https://doi.org/10.1029/2003GL017522

Kida S, Mitsudera H, Aoki S, Guo X, Ito S, Kobashi F, Komori N, Kubokawa A, Miyama T, Morie R, Nakamura H, Nakamura T, Nakano H, Nishigaki H, Nonaka M, Sasaki H, Sasaki YN, Suga T, Sugimoto S, Taguchi B, Takaya K, Tozuka T, Tsujino H, Usui N (2016) Oceanic fronts and jets around Japan: a review. "Hot Spots" in the Climate System. https://doi.org/10.1007/978-4-431-56053-1_1

Kobayashi S, Ota Y, Harada Y, Ebita A, Moriya M, Onoda H, Onogi K, Kamahori H, Kobayashi C, Endo H, Miyaoka K, Takahashi K (2015) The JRA-55 reanalysis: general specifications and basic characteristics. J Meteor Soc Jpn 93:5-48

Levitus S, Boyer TP (1994) World Ocean Atlas 1994. In: Temperature. NOAA Atlas NESDIS 4, vol 4. U.S. Government Printing Office, Washington, D.C., p 117

Levitus S, Burgett R, Boyer TP (1994) World Ocean Atlas 1994. In: Salinity. NOAA Atlas NESDIS 2, vol 3. U.S. Government Printing Office, Washington, D.C., p 99

Li R, Jing Z, Chen Z, Wu L (2017) Response of the Kuroshio extension path state to near-term global warming in CMIP5 experiments with MIROC4h. J Geophys Res 122(4):2871-2883

Liu ZJ, Minobe S, Sasaki YN, Terada M (2016) Dynamical downscaling of future sea level change in the western North Pacific using ROMS. J Oceanogr 72: 905-922

Matsuyama M, Ishidoya I, Iwata S, Kitade Y, Nagamatsu H (1999) Kyucho induced by intrusion of Kuroshio water in Sagami Bay, Japan. Cont Shelf Res 19:15611575

Moss RH, Edmonds J, Hibbard K (2010) The next generation of scenarios for climate change research and assessment. Nature 463(7282):747-756. https:// doi.org/10.1038/nature08823

Nishikawa H, Nishikawa S, Ishizaki H, Wakamatsu T, Ishikawa Y (2020) Detection of the Oyashio and Kuroshio fronts under the projected climate change in the 21st century. Prog Earth Planet Sci 7:29. https://doi.org/10.1186/s40645-020$00342-2$

Ohshima Kl, Simizu D, Ebuchi N, Morishima S, Kashiwase H (2017) Volume, heat, and salt transports through the Soya Strait and their seasonal and interannual variations. J Phys Oceanogr 47(5):999-1019. https://doi.org/10. 1175/JPO-D-16-0210.1

Oppenheimer M, Glavovic BC, Hinkel J, van de Wal R, Magnan AK, Abd-Elgawad R, Cai R, Cifuentes-Jara M, DeCont RM, Ghosh T, Hay J, Isla F, Marzeion B, Meyssignac B, Sebesvari Z (2019) Sea level rise and implications for low-lying islands, coasts and communities. In: IPCC Special Report on the Ocean and Cryosphere in a Changing Climate (SROCC) in press

Pedlosky J (1996) Ocean Circulation Theory. Springer-Verlag, Heidelberg, p 453

Qiu B, Hacker P, Chen S, Donohue KA, Watts DR, Mitsudera H, Hogg NG, Jayne SR (2006) Observations of the subtropical mode water evolution from the Kuroshio Extension System Study. J Phys Oceanogr 36:457-473

Sakamoto K, Tsujino H, Nakano H, Urakawa S, Toyoda T, Hirose N, Usui N, Yamanaka G (2019) Development of a 2-km resolution ocean model covering the coastal seas around Japan for operational application. Ocean Dyn 69:1181-1202

Sakamoto K, Yamanaka G, Tsujino H, Nakano H, Urakawa S, Usui N, Hirabara M, Ogawa K (2016) Development of an operational coastal model of the Seto Inland Sea, Japan. Ocean Dyn 66(1):77-97

Sakamoto T, Hasumi H, Ishii M, Emori S, Suzuki T, Nishimura T, Sumi A (2005) Responses of the Kuroshio and the Kuroshio Extension to global warming in a high-resolution climate model. Geophys Res Lett 32:14 
Sato Y, Yukimoto S, Tsujino H, Ishizaki H, Noda A (2006) Response of North Pacific Ocean circulation in a Kuroshio-Resolving ocean model to an Arctic Oscillation (AO)-like change in Northern Hemisphere atmospheric circulation due to greenhouse-gas forcing. J Meteorol Soc Jpn 84(2):295-309

SI-CAT (2020) SI-CAT report (in Japanese). https:/www.restec.or.jp/si-cat/ staticpages/index/202003-report.html. Accessed 28 Apr 2020.

Sun C, Feng M, Matear RJ, Chamberlain MA, Craig P, Ridgway KR, Schiller A (2012) Marine downscaling of a future climate scenario for Australian boundary currents. J Clim 25:2947-2962

Suzuki T, Yamazaki D, Tsujino H, Komuro Y, Nakano H, Urakawa S (2018) A dataset of continental river discharge based on JRA-55 for use in a global ocean circulation model. J Oceanogr 74:421-429

Taylor KE, Stouffer RJ, Meehl GA (2012) An overview of CMIP5 and the experiment design. Bull Am Meteorol Soc 93(4):485-498. https://doi.org/10 1175/BAMS-D-11-00094.1

Toste R, de Freitas Assad LP, Landau L (2017) Downscaling of the global HadGEM2-ES results to model the future and present-day ocean conditions of the southeastern Brazilian continental shelf. Clim Dyn. https://doi.org/10. 1007/s00382-017-3911-7

Troselj J, Imai Y, Ninomiya J, Mori N (2018) Coastal current downscaling emphasizing freshwater impact on Ibaraki coast. J Jpn Soc Civil Eng B2 74(2):1357-1362

Tsujino H, Motoi T, Ishikawa I, Hirabara M, Nakano H, Yamanaka G, Yasuda T, Ishizaki H (2010) Reference manual for the Meteorological Research Institute Community Ocean Model (MRI.COM) version 3. In: Technical Reports of the MRI 59

Tsujino H, Nakano H, Motoi T (2008) Mechanism of currents through the straits of the Japan Sea: mean state and seasonal variation. J Oceanogr 64:141-161

Tsujino H, Nakano H, Sakamoto K, Urakawa S, Hirabara M, Ishizaki H, Yamanaka G (2017) Reference manual for the Meteorological Research Institute Community Ocean Model version 4 (MRI.COMv4). In: Technical Reports of the MRI 80

Usui N, Wakamatsu T, Tanaka Y, Hirose N, Toyoda T, Nishikawa S, Fujii Y, Takatsuki Y, Igarashi H, Nishikawa H, Ishikawa Y, Kuragano T, Kamachi M (2017) Fourdimensional variational ocean reanalysis: a 30-year high-resolution dataset in the western North Pacific (FORA-WNP30). J Oceanogr 73:205-233

Vuuren DP, Edmonds J, Kainuma M, Riahi K, Thomson A, Hibbard K, Hurtt GC, Kram T, Krey V, Lamarque JF, Masui T, Meinshausen M, Nakicenovic N, Smith SJ, Rose SK (2011) The representative concentration pathways: an overview. Clim Chang 109(1-2):5-31. https://doi.org/10.1007/s10584-011-0148-z

Watanabe M, Suzuki T, O'shi R, Komuro Y, Wanatabe S, Emori S, Takemura T, Chikira M, Ogura T, Sekiguchi M, Takata K, Yamazaki D, Yokohata T, Nozawa T, Hasumi H, Tatebe H, Kimoto M (2010) Improved climate simulation by MIROC5: mean states, variability, and climated sensitivity. J Clim 23:6312-6335

Xiu P, Chai F, Curchitser EN, Castruccio FS (2018) Future changes in coastal upwelling ecosystems with global warming: the case of the California Current System. Sci Rep 8:2866. https://doi.org/10.1038/s41598-018-21247-7

Yasuda I (2003) Hydrographic structure and variability in the Kuroshio-Oyashio Transition Area. J Oceanogr 59:389-402

Yukimoto S, Adachi Y, Hosaka M, Sakami T, Yoshimura H, Hirabara M, Tanaka TY, Shindo E, Tsujino H, Deushi M, Mizuta R, Yabu S, Obata A, Nakano H, Koshiro T, Ose T, Kito A (2012) A new global climate model of the Meteorological Research Institute: MRI-CGCM3: model description and basic performance. $J$ Meteorol Soc Jpn 90A:23-64

\section{Publisher's Note}

Springer Nature remains neutral with regard to jurisdictional claims in published maps and institutional affiliations.

\section{Submit your manuscript to a SpringerOpen ${ }^{\circ}$ journal and benefit from:}

- Convenient online submission

- Rigorous peer review

- Open access: articles freely available online

- High visibility within the field

- Retaining the copyright to your article

Submit your next manuscript at $\boldsymbol{\nabla}$ springeropen.com 